\title{
Numerical Analysis on Chaotic Vibration of Drive System for a Movable Tooth Piezoelectric Motor
}

\author{
Chong Li, ${ }^{1,2}$ Jichun Xing, ${ }^{3}$ Jiwen Fang, ${ }^{1,2}$ and Zhong Zhao ${ }^{1,2}$ \\ ${ }^{1}$ School of Mechanical Engineering, Jiangsu University of Science and Technology, Zhenjiang 212003, China \\ ${ }^{2}$ Jiangsu Provincial Key Laboratory of Advanced Manufacturing for Marine Mechanical Equipment, \\ Jiangsu University of Science and Technology, Zhenjiang 212003, China \\ ${ }^{3}$ School of Mechanical Engineering, Yanshan University, Qinhuangdao 066004, China \\ Correspondence should be addressed to Jichun Xing; xingjichun@ysu.edu.cn
}

Received 24 March 2017; Revised 27 July 2017; Accepted 22 August 2017; Published 12 October 2017

Academic Editor: Carlo Trigona

Copyright (C) 2017 Chong Li et al. This is an open access article distributed under the Creative Commons Attribution License, which permits unrestricted use, distribution, and reproduction in any medium, provided the original work is properly cited.

\begin{abstract}
The nonlinear dynamic equations of the drive system for movable tooth piezoelectric motor are established. Using these equations, the chaotic vibrations of the system are investigated. The results show that chaotic vibrations occur in the movable tooth drive system under some parameters. The average mesh stiffness, theoretical radius, and wave generator offset significantly influence the nonlinear chaotic vibrations of the drive system of the movable tooth piezoelectric motor. The ranges for the system parameters that lead to a motor with bad dynamics are shown. The results can be used to predict the dynamic load and optimize power density of the proposed piezoelectric motor.
\end{abstract}

\section{Introduction}

Piezoelectric motors have been widely utilized in fields such as electromechanical actuating, mechanical energy harvesting, aeronautics, and astronautics [1-3]. In 1988, Kurosawa et al. proposed a cylinder-shaped piezoelectric motor in which the bending modes were used to increase its mechanical output [4]. In 2002, Koc et al. proposed a piezoelectric motor with two orthogonal bending modes of a hollow cylinder; later the motor was used in camera of phones by Samsung Corp [5]. What is more, in 2014, Mashimo designed a micropiezoelectric motor in which the size of stator was only one cubic millimeter [6].

Meanwhile, inchworm piezoelectric actuator is the special friction type piezoelectric motor. In 2003, Mrad et al. developed a motor that was designed based on the classical inchworm principle, and a hybrid control method was used for the motor [7]. In 2010, A ultracompact, zero-power magnetic latching piezoelectric inchworm motor was proposed. With a $50 \mathrm{kHz}$ driving frequency, precision of $5 \mu \mathrm{m}$ at a scalable full stroke of $5 \mathrm{~mm}$ and a speed of $10 \mathrm{~mm} / \mathrm{s}$ were achieved [8]. Besides, Li et al. designed an inchworm type rotary actuator in 2014. In the motor, six piezostacks and flexure hinges were used to realize large rotation ranges with high accuracy both in the forward and in backward motions. The test results indicate that the maximum output torque was $19.6 \mathrm{Nmm}$ [9]. What is more, $\mathrm{Gu}$ and Xing proposed a rotary inchworm piezoelectric motor. The motor has advantages such as high positioning accuracy, large output torque, and large travel [10].

Although the piezoelectric motors have been widely used in modern life. However, the friction between the stator and the rotor in piezoelectric motors limits its output torque and operating life.

Hence, a noncontact piezoelectric motor in which the fluid between the stator and rotor was proposed by Yamayoshi and Hirose in 1992 [11]. In 2009, a noncontact piezoelectric motor with two flexural standing wave vibration disks was proposed by Yamayoshi et al., and the rotating speed of which is up to $2000 \mathrm{rpm}$ at a very low driving voltage of $3 \mathrm{~V}$ [12]. In 2012, a noncontact piezoelectric actuator with spherical rotors was designed by Chen et al., and a maximum rotational speed of $521 \mathrm{r} / \mathrm{min}$ was obtained under excitation voltage of $300 \mathrm{~V}$ [13]. Two years later, Qiu et al. proposed a noncontact piezoelectric rotary motor that was modulated by giant electrorheological fluid [14]. In short, the noncontact 

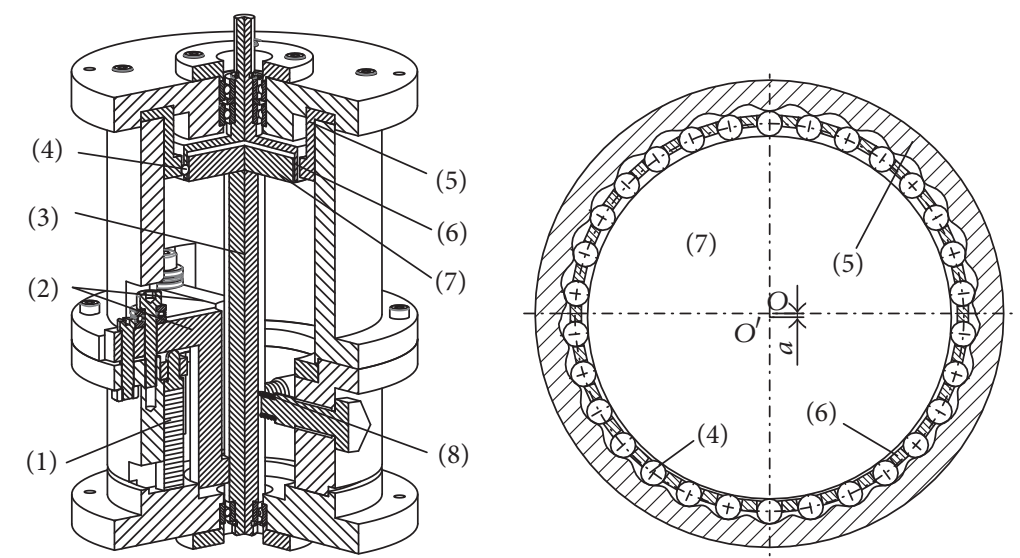

FIGURE 1: Movable tooth piezoelectric motor. (1) Piezoelectric actuator; (2) z-shaped rod; (3) swaying rod; (4) movable tooth; (5) rigid cog; (6) rotor; (7) wave generator; (8) spring.
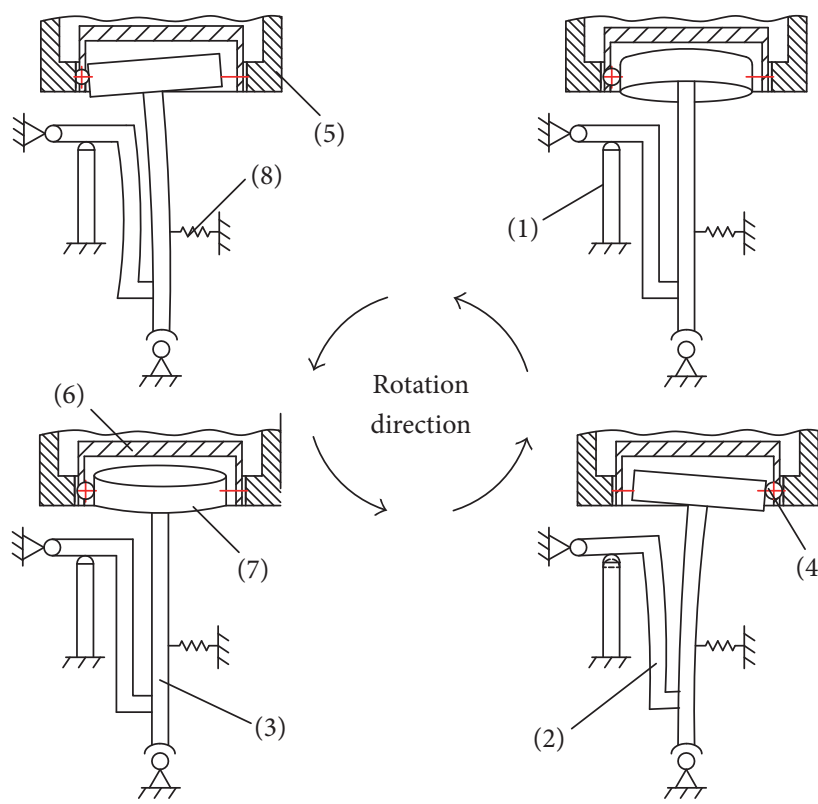

Rotation

direction
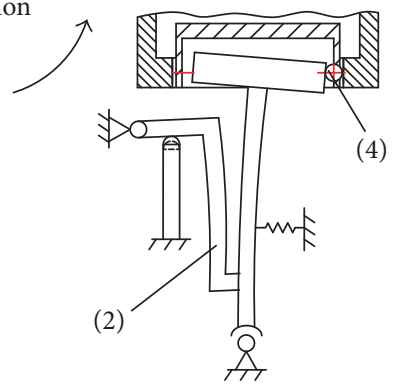

FIGURE 2: Working principle of movable tooth piezoelectric motor.

piezoelectric motors eliminated the friction between the stator and rotor and increased the efficiency and lifetime. However, the output torque of which is too small to satisfy the practical need.

Therefore, the authors proposed a movable tooth piezoelectric motor, and, hence, a larger transmission ratio and a larger output torque of which can be obtained [15]. The structure and working principle of the proposed motor are shown in Figures 1 and 2. The motor consists of driving system and transmission system. The driving system includes piezoelectric actuator (1), z-shaped rod (2), swaying rod (3) and adjusting spring (8), the transmission system contains movable tooth (4), rigid $\operatorname{cog}(5)$, rotor (6), and wave generator (7).

The driving source of the motor consists of two piezoelectric actuators with a phase difference of 90 degrees. When the piezoelectric actuators are subject to cosine signals with a positive bias and 90 degrees phase difference, they generate an axial elongation. With z-shaped rod, the swaying rod is pushed toward the side of the springs. When the voltage of the exciting signals returns to zero, the swaying rod returns to the initial position under the elastic force of the springs. Then, the swaying rod swings back and forth in two directions performing a continuous harmonic wave on wave generator. Here, 30 movable teeth and 29 rigid cog teeth are used. With the effect of movable tooth drive, the rotation can achieve a transmission ratio of 30 . Here, the movable teeth are steel balls and its diameter is $1 \mathrm{~mm}$. When working, the movable teeth locate in the groove of the rotor. The rigid $\operatorname{cog}$ is formed by tooth profile equation, and the equation can be expressed by

$$
\begin{aligned}
X= & b \cos \left(\theta-\arcsin \left[\frac{a \sin \left(\left(i_{c p}-1\right) \theta\right)}{b}\right]\right) \\
& +a \cos \left(i_{c p} \theta\right) \pm r_{p} \cos \psi,
\end{aligned}
$$




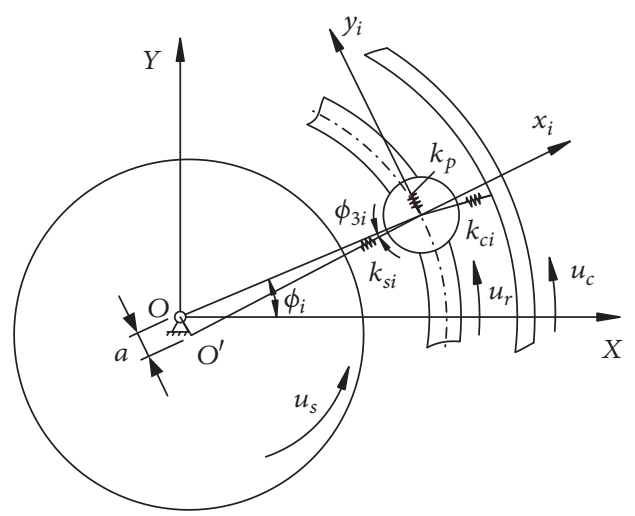

(a) Relative displacement

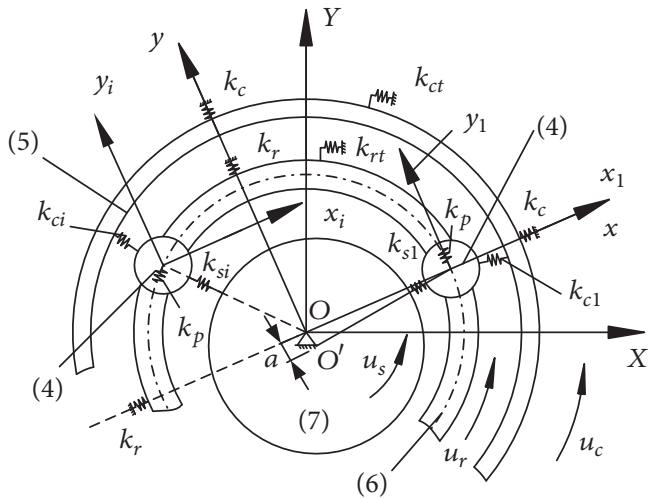

(b) Forces of movable tooth system

FIgURE 3: Dynamic model of drive system of movable tooth piezoelectric motor.

$$
\begin{aligned}
Y= & b \sin \left(\theta-\arcsin \left[\frac{a \sin \left(\left(i_{c p}-1\right) \theta\right)}{b}\right]\right) \\
& +a \sin \left(i_{c p} \theta\right) \pm r_{p} \sin \psi,
\end{aligned}
$$

where $\theta$ is rotational angle of the rotor; $\psi$ is the angle between $x$-axis and tangent of central trajectory of movable tooth; $b$ is coefficient, $b=r_{s}+r_{p} ; r_{s}$ and $r_{p}$ are radius of wave generator and movable tooth.

The proposed movable tooth piezoelectric motor is a nonlinear coupled system, and the nonlinear coupled dynamics have an important influence on operating behavior of the motor. In [16], the nonlinear free vibration of driving system of the movable tooth piezoelectric motor was studied. The chaotic vibrations of the drive system influence the dynamics of the motor, which will decrease the load carrying capacity. In [17], the chaotic vibrations of driving system for the piezoelectric motor were investigated. The results show that the chaotic vibrations of the driving system for the motor occur under some parameters. However, the chaotic vibrations characteristics of the transmission system for the piezoelectric motor are unknown.

So, the purpose of this paper is to reveal the influence of chaotic vibrations of the transmission system on dynamics of the proposed motor. Using Runge-Kutta numerical method, the nonlinear dynamic performance and the effect of average mesh stiffness, theoretical radius, and wave generator offset on chaotic vibrations characteristics are investigated. The results can be used to predict the dynamic load and optimize power density of the motor.

\section{Nonlinear Dynamic Equations}

Dynamic model of drive system of movable tooth piezoelectric motor is shown in Figure 3. Figures 3(a) and 3(b) are the relative displacement between movable teeth and central elements (rotor, rigid cog, and wave generator) and forces of movable tooth system, respectively. In Figure 3, the coordinate system $O X Y$ is attached to the foundation, oxy to rotor 6 , and $o_{i} x_{i} y_{i}$ to the $i$ th movable tooth. Subscripts $s, c, r, p$ represent, respectively, wave generator, rigid cog, rotor, and movable tooth. Besides, $x_{j}, y_{j}, u_{j}$ represent $x, y$ direction and circumferential direction linear displacement $\left(j=s, c, r, p_{1}, \ldots, p_{z}\right)$. Wave generator offset $a$ is the distance between rotor center $O$ and wave generator center $O^{\prime}$.

From Figure 3(a), the projection of relative displacement from central elements to movable teeth along meshing line can be written as

$$
\begin{aligned}
& \delta_{s i}=\left(x_{s}-x_{p i}\right) \cos \phi_{1 i}+\left(y_{s}-y_{p i}\right) \sin \phi_{1 i}+u_{s} \sin \phi_{3 i}, \\
& \delta_{c i}=\left(x_{c}-x_{p i}\right) \cos \theta_{i}+\left(y_{c}-y_{p i}\right) \sin \theta_{i}-u_{c} \sin \phi_{\theta i}, \\
& \delta_{r i}=\left(x_{p i}-x_{r}\right) \sin \phi_{i}+\left(y_{r}-y_{p i}\right) \cos \phi_{i}-u_{r},
\end{aligned}
$$

where $\phi_{1 i}=\phi_{i}+\phi_{3 i}, \phi_{\theta i}=\phi_{i}-\theta_{i} . \theta_{i}$ is angular displacement of elements, $\phi_{i}$ is the angle between line $o o_{i}$ and coordinate axis $x$ direction, $o o_{n}$ is the line from center of the $n$th movable tooth and rotor center, $\phi_{3 i}$ is the angle between line $o o_{3 i}$ and coordinate axis $x$ direction, and $o o_{3 i}$ is the line from center of the $n$th movable tooth and vibrator center.

From Figure 3(b), the linear dynamic equations of drive system for movable tooth piezoelectric motor can be expressed by

$$
\begin{gathered}
m_{s} \ddot{x}_{s}+\sum_{i=1}^{Z} k_{s} \delta_{s i} \cos \phi_{1 i}+k_{s z} x_{s}=0, \\
m_{s} \ddot{y}_{s}+\sum_{i=1}^{Z} k_{s} \delta_{s i} \sin \phi_{1 i}+k_{s z} y_{s}=0, \\
\left(\frac{I_{s}}{r_{s}^{2}}\right) \ddot{u}_{s}-\sum_{i=1}^{Z} k_{s} \delta_{s i} \sin \phi_{3 i}+k_{s t} u_{s}=\frac{T_{s}}{r_{s}}, \\
m_{c} \ddot{x}_{c}+\sum_{i=1}^{Z} k_{c} \delta_{c i} \cos \theta_{i}+k_{c z} x_{c}=0, \\
m_{c} \ddot{y}_{c}+\sum_{i=1}^{Z} k_{c} \delta_{c i} \sin \theta_{i}+k_{c z} y_{c}=0,
\end{gathered}
$$




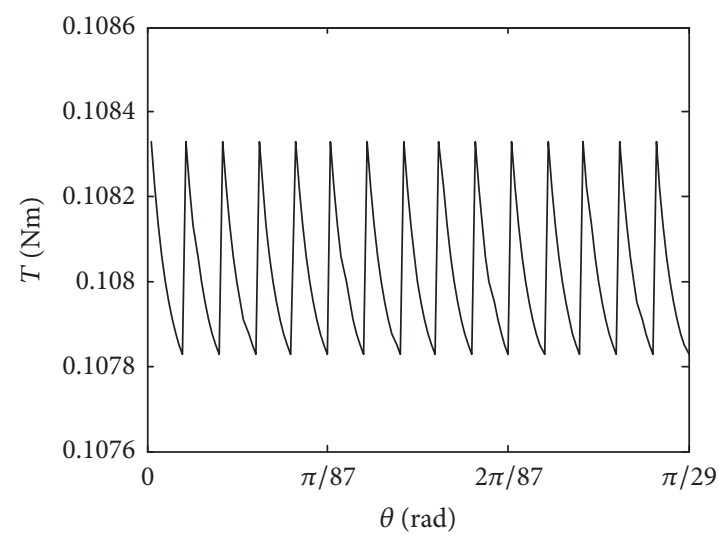

(a) Multiperiod

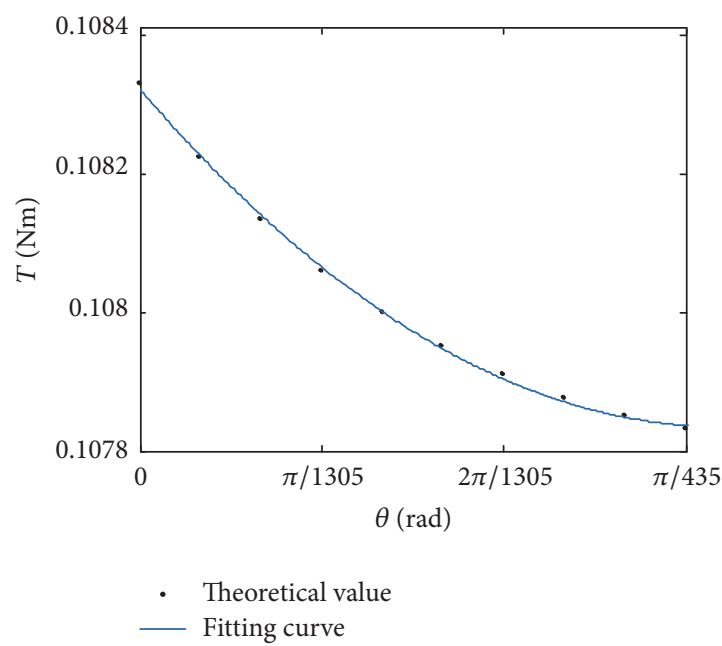

(b) Single-period

FIGURE 4: Output torque changes with rotational corner of rotor.

$$
\begin{array}{r}
\left(\frac{I_{c}}{r_{c}^{2}}\right) \ddot{u}_{c}-\sum_{i=1}^{Z} k_{c} \delta_{c i} \sin \phi_{\theta i}+k_{c t} u_{c}=0, \\
m_{r} \ddot{x}_{r}-\sum_{i=1}^{Z} k_{r} \delta_{r i} \sin \phi_{i}+k_{r z} x_{r}=0, \\
m_{r} \ddot{y}_{r}+\sum_{i=1}^{Z} k_{r} \delta_{r i} \cos \phi_{i}+k_{r z} y_{r}=0, \\
\left(\frac{I_{r}}{r_{r}^{2}}\right) \ddot{u}_{r}-\sum_{i=1}^{Z} k_{r} \delta_{r i}+k_{r t} u_{r}=0,
\end{array}
$$$$
m_{p} \ddot{x}_{p i}-k_{c} \delta_{c i} \cos \theta_{i}+k_{r} \delta_{r i} \sin \phi_{i}-k_{s} \delta_{s i} \cos \phi_{1 i}=0 \text {, }
$$$$
m_{p} \ddot{y}_{p i}-k_{c} \delta_{c i} \sin \theta_{i}-k_{r} \delta_{r i} \cos \phi_{i}-k_{s} \delta_{s i} \sin \phi_{1 i}=0 \text {, }
$$

$$
\left(\frac{I_{p}}{r_{p}^{2}}\right)\left(\ddot{u}_{i}+\ddot{u}_{j}\right)=0,
$$

where $m_{j}, I_{j}$ are mass and relative mass of each element, $k_{j}$, $k_{j z}, k_{j t}$ represent the mesh stiffness and radial and tangent supporting stiffness between the movable teeth and central elements, $r_{i}$ is theoretical radius of elements, and $T_{s}$ is output torque of wave generator.

The output torque of movable tooth piezoelectric motor changes with rotational corner of rotor is shown in Figure 4. In Figure 4(a), the output torque jump at $\theta=n \cdot \pi / 435$. And in Figure 4(b), the output torque equation in single-period is complex, applying polynomial curves to fit torque equation, and yields

$$
T_{1}=\tau_{1} \theta^{2}+\tau_{2} \theta+\tau_{3} \quad\left(0 \leq \theta<\frac{\pi}{435}\right)
$$

where $\tau_{1}, \tau_{2}, \tau_{3}$ are fitting coefficients.
Applying Fourier transform, (3) can be written as

$$
\begin{aligned}
T(\theta) & =\frac{a_{0}}{2}+\sum_{i=1}^{n}\left(a_{n} \cos \frac{2 n \pi \theta}{\tau}+b_{n} \sin \frac{2 n \pi \theta}{\tau}\right) \\
& =\frac{a_{0}}{2}+\sum_{i=1}^{n}\left(\sqrt{a_{n}^{2}+b_{n}^{2}} \sin \left(\frac{2 n \pi \theta}{\tau}+\phi_{T}\right)\right),
\end{aligned}
$$

where $a_{n}$ and $b_{n}$ are Fourier coefficients,

$$
\begin{aligned}
\phi_{T} & =\arctan \frac{a_{n}}{b_{n}}, \\
a_{0} & =\frac{2}{3} \tau^{2} \tau_{1}+\tau \tau_{2}+2 \tau_{3}, \\
a_{n} & =\frac{2}{\tau} \int_{0}^{\tau} T_{1}(\theta) \cos \frac{2 n \pi \theta}{\tau} \mathrm{d} \theta=\frac{\tau^{2} \tau_{1}}{\pi^{2} n^{2}}, \\
b_{n} & =\frac{2}{\tau} \int_{0}^{\tau} T_{1}(\theta) \sin \frac{2 n \pi \theta}{\tau} \mathrm{d} \theta=-\frac{\tau^{2} \tau_{1}+\tau \tau_{2}}{\pi n} .
\end{aligned}
$$

Assume that rotational angle increment and output torque increment of rotor are $\delta \theta$ and $\delta T_{r}$, respectively. So, the Taylor series of $T_{r}$ at $\theta=\theta_{0}$ can be expressed by

$$
\begin{aligned}
T_{r}= & T_{r 0}+\delta T_{r} \\
= & T\left(\theta_{0}\right)+T^{\prime}\left(\theta_{0}\right) \delta \theta+\frac{1}{2} T^{\prime \prime}\left(\theta_{0}\right)(\delta \theta)^{2}+\cdots \\
= & \frac{a_{0}}{2}+\sum_{i=1}^{n}\left(\sqrt{a_{n}^{2}+b_{n}^{2}} \sin \left(\frac{2 n \pi \theta_{0}}{\tau}+\phi_{T}\right)\right) \\
& +\sum_{i=1}^{n}\left(\frac{2 n \pi}{\tau} \sqrt{a_{n}^{2}+b_{n}^{2}} \cos \left(\frac{2 n \pi \theta_{0}}{\tau}+\phi_{T}\right)\right) \delta \theta
\end{aligned}
$$




$$
\begin{aligned}
& -\sum_{i=1}^{n}\left(\frac{4 n^{2} \pi^{2}}{\tau^{2}} \sqrt{a_{n}^{2}+b_{n}^{2}} \sin \left(\frac{2 n \pi \theta_{0}}{\tau}+\phi_{T}\right)\right)(\delta \theta)^{2} \\
& +\cdots
\end{aligned}
$$

Output torque increment of rotor is

$\delta T_{r}$

$$
\begin{aligned}
= & \sum_{i=1}^{n}\left(\frac{2 n \pi}{\tau} \sqrt{a_{n}^{2}+b_{n}^{2}} \cos \left(\frac{2 n \pi \theta_{0}}{\tau}+\phi_{T}\right)\right) \delta \theta \\
& -\sum_{i=1}^{n}\left(\frac{4 n^{2} \pi^{2}}{\tau^{2}} \sqrt{a_{n}^{2}+b_{n}^{2}} \sin \left(\frac{2 n \pi \theta_{0}}{\tau}+\phi_{T}\right)\right)(\delta \theta)^{2} \\
& +\cdots
\end{aligned}
$$

Hence, the relationship between output torque $T$ and meshing force between movable tooth and rotor $F_{r j}$ can be written as

$$
T=\sum_{j=1}^{n} F_{r j} S_{j}=\sum_{j=1}^{n} k_{r} S_{j}^{2} \delta \theta .
$$

From (9), the nonlinear meshing stiffness between movable tooth and rotor can be expressed by

$$
\begin{aligned}
k_{r} & =\frac{\sqrt{a_{n}^{2}+b_{n}^{2}}}{S_{j}^{2}} \sum_{i=1}^{n}\left[\frac{2 n \pi}{\tau} \cos \left(\frac{2 n \pi \theta_{0}}{\tau}+\phi_{T}\right)\right. \\
& \left.-\frac{4 n^{2} \pi^{2}}{\tau^{2}} \sin \left(\frac{2 n \pi \theta_{0}}{\tau}+\phi_{T}\right) \delta \theta+\cdots\right]=\frac{\sqrt{a_{n}^{2}+b_{n}^{2}}}{S_{j}^{2}} \\
& \cdot \sum_{i=1}^{n}\left[A_{k}-\frac{2 n \pi A_{k}}{\tau} \tan \left(\frac{2 n \pi \theta_{0}}{\tau}+\phi_{T}\right) \delta \theta+\cdots\right] \\
& =\bar{k}_{r}+\Delta k_{r},
\end{aligned}
$$

where

$$
\begin{aligned}
\Delta k_{r} & =-\frac{2 n \pi A_{k} \sqrt{a_{n}^{2}+b_{n}^{2}}}{\tau S_{j}^{2}} \sum_{i=1}^{n} \tan \left(\frac{2 n \pi \theta_{0}}{\tau}+\phi_{T}\right) \delta \theta, \\
\bar{k}_{r} & =\frac{\sqrt{a_{n}^{2}+b_{n}^{2}}}{S_{j}^{2}} \sum_{i=1}^{n} A_{k}, \\
A_{k} & =\frac{2 n \pi}{\tau} \cos \left(\frac{2 n \pi \theta_{0}}{\tau}+\phi_{T}\right) .
\end{aligned}
$$

Following the same approach, the nonlinear meshing stiffness between movable tooth and wave generator, rigid cog can be written as

$$
\begin{aligned}
& k_{s}=\bar{k}_{s}-\frac{2 n \pi}{\tau} \tan \left(\frac{2 n \pi \theta_{0}}{\tau}+\phi_{T}\right) \delta \theta \bar{k}_{s}=\bar{k}_{s}+\Delta k_{s}, \\
& k_{c}=\bar{k}_{c}-\frac{2 n \pi}{\tau} \tan \left(\frac{2 n \pi \theta_{0}}{\tau}+\phi_{T}\right) \delta \theta \bar{k}_{c}=\bar{k}_{c}+\Delta k_{c} .
\end{aligned}
$$

Further, substituting (10) and (12) into (3), the nonlinear dynamic equations of movable tooth drive system can be expressed by

$$
\mathbf{M} \ddot{\mathbf{q}}+\mathbf{K q}=\mathbf{F}+\Delta \mathbf{F},
$$

where $\mathbf{M}, \mathbf{K}, \mathbf{q}$ are mass matrix, stiffness matrix, and generalized coordinates array of the system; $\mathbf{F}$ and $\Delta \mathbf{F}$ are outer forces array and nonlinear meshing forces increment array, $\Delta \mathbf{F}=B_{k} u_{i} \varepsilon \Lambda$; and $\Lambda$ is array that contains only sine and cosine element.

$$
B_{k}=\frac{2 n \pi A_{k} \sqrt{a_{n}^{2}+b_{n}^{2}}}{\tau S_{j}^{2}} \sum_{i=1}^{n} \tan \left(\frac{2 n \pi \theta_{0}}{\tau}+\phi_{T}\right) .
$$

\section{Results and Discussion}

Equation (13) can be resolved by using a Matlab software tool that involves the fourth-order Runge-Kutta method. The time step is $T / 100$, and the total time is $400 T$. Because the beginning of the calculation yields unstable responses, we discard the response of the first 300 periods and use only the response of the final $100 T$, where $T$ is the period of the system vibration. Torsional vibration behaves obviously in movable tooth drive system, so the torsional vibration response of central elements is selected to discuss. The parameters of the numerical example are given in Table 1.

3.1. Influence of Average Mesh Stiffness on Chaotic Vibration. Figure 5 gives bifurcation diagrams of torsional vibration of movable tooth drive system for average mesh stiffness $\left(k_{s-\mathrm{av}}, k_{c \text {-av }}, k_{p \text {-av }}\right)$ varying from $(0,0,0)$ to $\left(1 \times 10^{8}, 3 \times\right.$ $\left.10^{8}, 1 \times 10^{8}\right)$. Here, the bifurcation diagrams can show sudden changes of the vibration stage when some parameters changes. Moreover, the Poincare section method is utilized to obtain the bifurcation diagrams. From Figure 5, the following are known.

(1) When $k_{s-\mathrm{av}}=1 \times 10^{7} \mathrm{~N} / \mathrm{m}, 1.7 \times 10^{7} \mathrm{~N} / \mathrm{m}, 3.8 \times$ $10^{7} \mathrm{~N} / \mathrm{m}, 9.2 \times 10^{7} \mathrm{~N} / \mathrm{m}$, the bifurcation diagram of wave generator shows sudden changes of vibration state. When $k_{s \text {-av }}<1 \times 10^{7} \mathrm{~N} / \mathrm{m}$, the response amplitude is at stable state and the system tends to do quasiperiodic motion.

(2) Similarly, when $k_{c \text {-av }}=6 \times 10^{3} \mathrm{~N} / \mathrm{m}, 3.3 \times 10^{7} \mathrm{~N} / \mathrm{m}$, $6.7 \times 10^{7} \mathrm{~N} / \mathrm{m}, 8 \times 10^{7} \mathrm{~N} / \mathrm{m}$ and $k_{p \text {-av }}=2 \times 10^{3} \mathrm{~N} / \mathrm{m}, 1.2 \times$ $10^{7} \mathrm{~N} / \mathrm{m}, 4 \times 10^{7} \mathrm{~N} / \mathrm{m}, 7 \times 10^{7} \mathrm{~N} / \mathrm{m}$, the bifurcation diagrams of rigid $\operatorname{cog}$ and rotor behave in sudden changes of vibration state.

(3) Changes of bifurcation diagram with average mesh stiffness of elements are similar. However, the starting point of sudden changes is different for each central element. It is because the dimension and natural frequency of each element are different, and the vibration intensity varies from one element to another. So this is the reason why the starting point of sudden changes is different.

Figure 6 shows Poincare map of torsional vibration response for different average mesh stiffness. Poincare map uses simple discrete mapping points to show continuous motions. Taking one mapping point each exciting period, 
TABle 1: Parameters of example system.

\begin{tabular}{lcccc}
\hline Parameters & Rotor & Rigid cog & Wave generator & Movable tooth \\
\hline Mass (kg) & $1.31 \times 10^{-2}$ & $5.64 \times 10^{-2}$ & $2.59 \times 10^{-2}$ & $3.30 \times 10^{-2}$ \\
Equivalent mass (kg) & $9.34 \times 10^{-2}$ & $8.41 \times 10^{-2}$ & $1.30 \times 10^{-2}$ & $1.32 \times 10^{-2}$ \\
Diameter (mm) & $10 \sim 50$ & $10 \sim 50$ & $5 \sim 50$ & 2 \\
Radial support stiffness (N/m) & $5 \times 10^{8}$ & $5 \times 10^{8}$ & $5 \times 10^{8}$ & 0 \\
Tangent support stiffness (N/m) & 0 & $1 \times 10^{9}$ & $0 \sim 1 \times 10^{8}$ & 0 \\
Mesh stiffness (N/m) & $0 \sim 1 \times 10^{8}$ & $0 \sim 3 \times 10^{8}$ & 0 \\
\hline
\end{tabular}

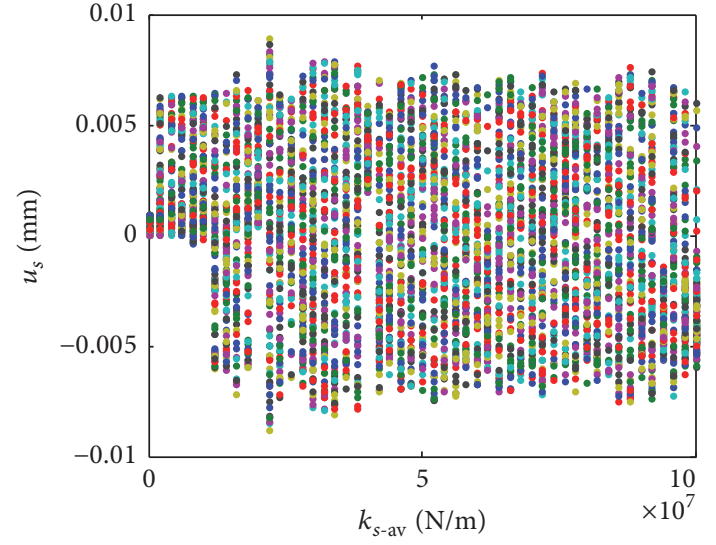

(a) $k_{s \text {-av }}=0 \sim 1 \times 10^{8} \mathrm{~N} / \mathrm{m}$

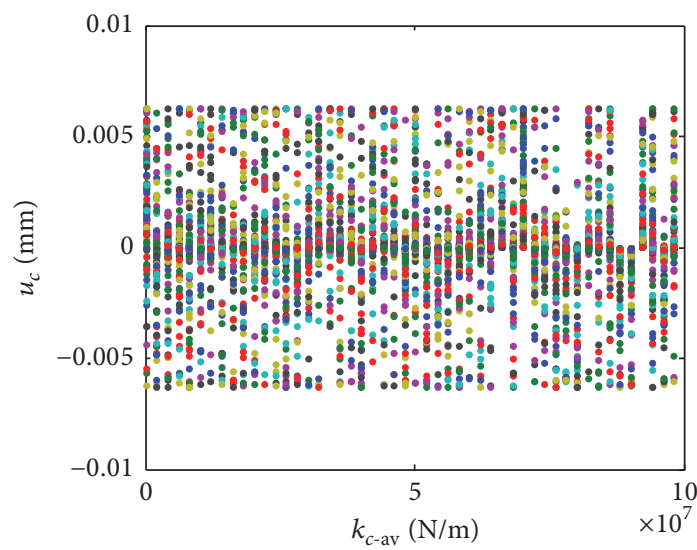

(c) $k_{c \text {-av }}=0 \sim 1 \times 10^{8} \mathrm{~N} / \mathrm{m}$

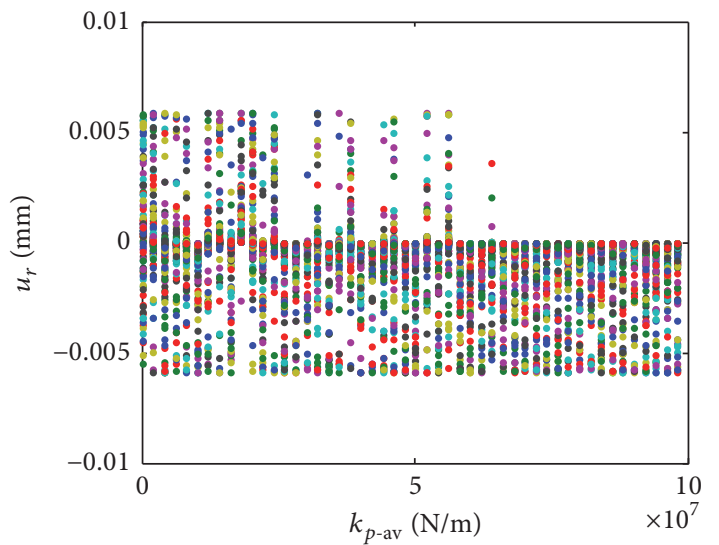

(e) $k_{p \text {-av }}=0 \sim 1 \times 10^{8} \mathrm{~N} / \mathrm{m}$

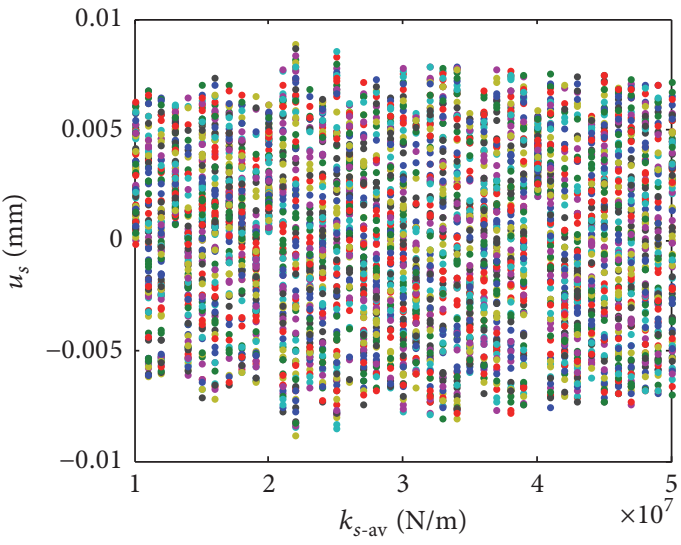

(b) $k_{s \text {-av }}=1 \times 10^{7} \sim 7 \times 10^{7} \mathrm{~N} / \mathrm{m}$

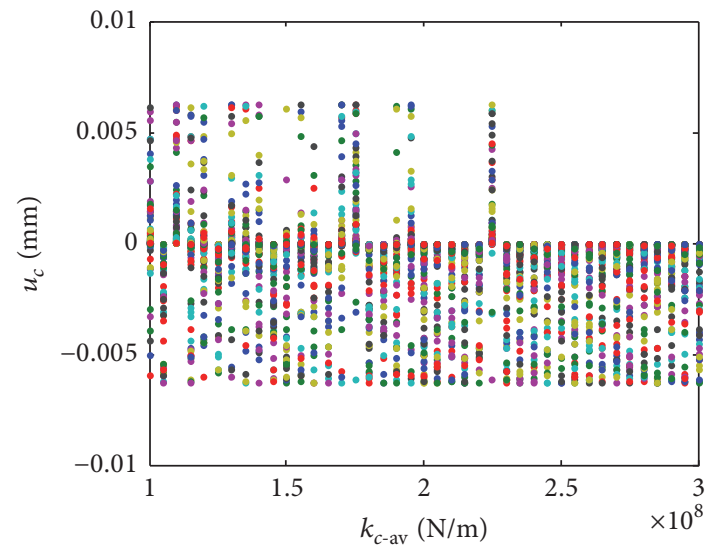

(d) $k_{c \text {-av }}=1 \times 10^{8} \sim 3 \times 10^{7} \mathrm{~N} / \mathrm{m}$

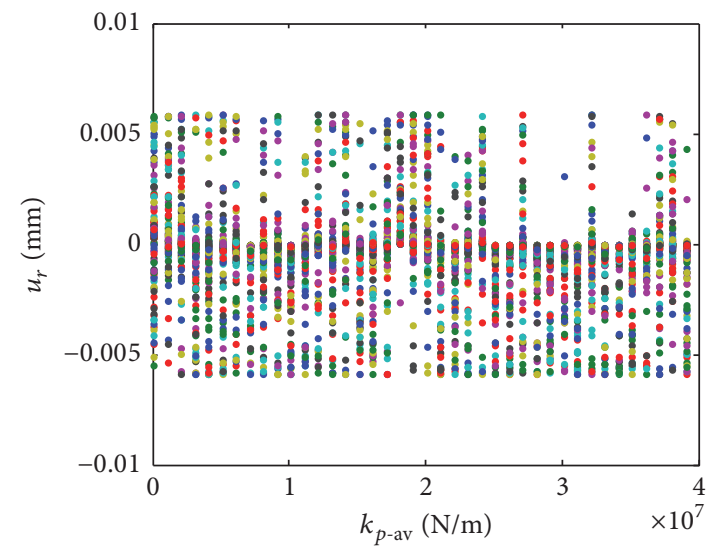

(f) $k_{p \text {-av }}=0 \sim 4 \times 10^{7} \mathrm{~N} / \mathrm{m}$

FIGURE 5: Bifurcation with average mesh stiffness. 


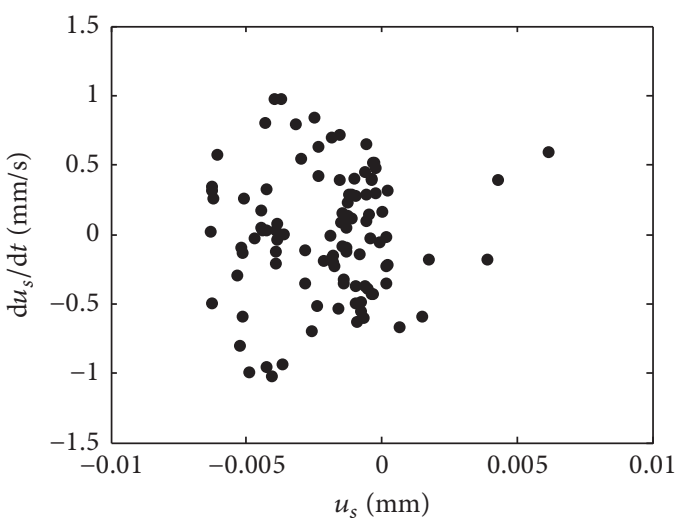

(a) $k_{s-\mathrm{av}}=1 \times 10^{7} \mathrm{~N} / \mathrm{m}$

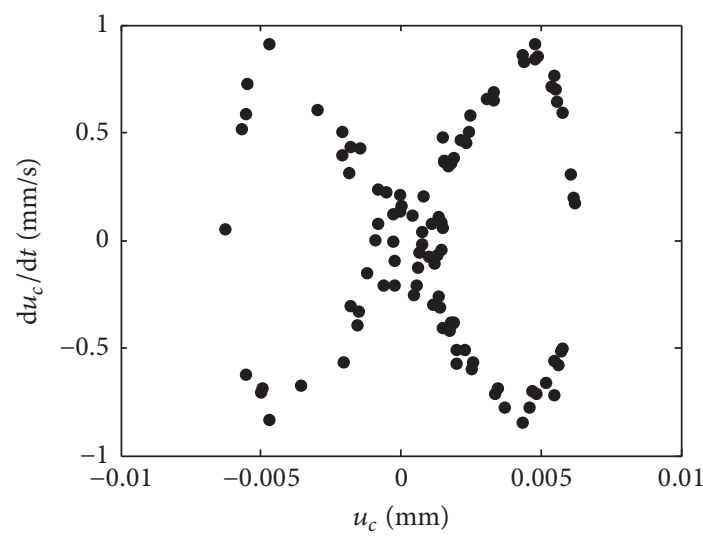

(c) $k_{c \text {-av }}=6 \times 10^{3} \mathrm{~N} / \mathrm{m}$

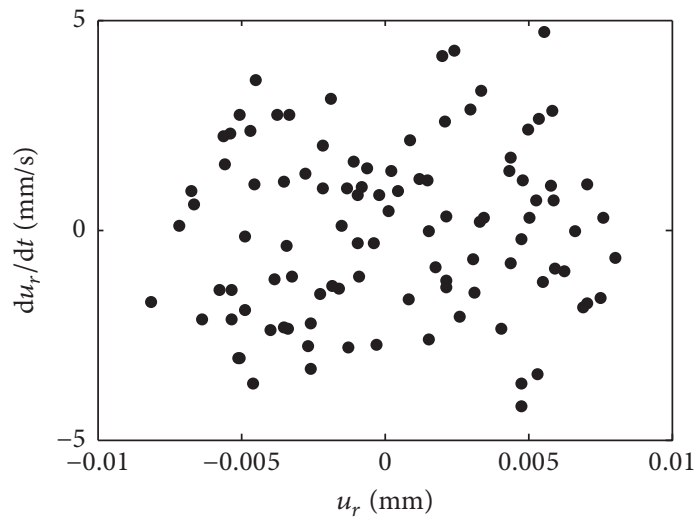

(e) $k_{p \text {-av }}=2 \times 10^{3} \mathrm{~N} / \mathrm{m}$

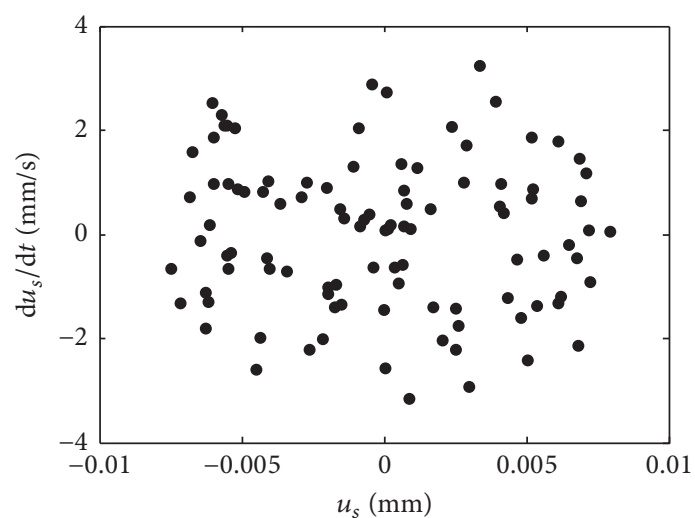

(b) $k_{s-\mathrm{av}}=3.8 \times 10^{7} \mathrm{~N} / \mathrm{m}$

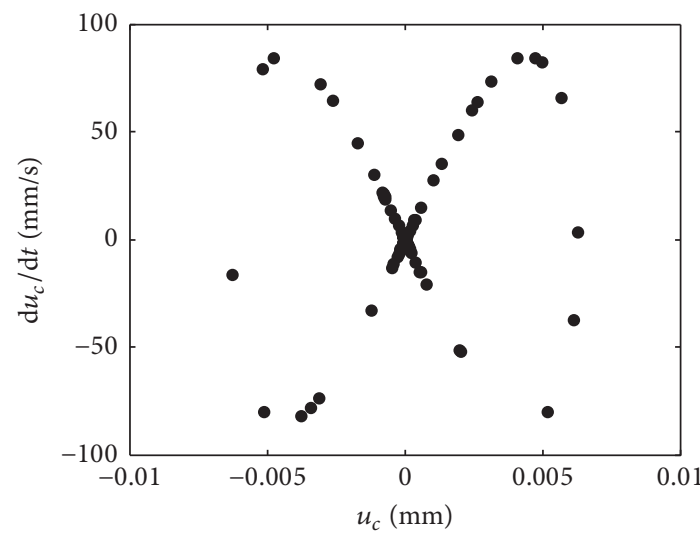

(d) $k_{c \text {-av }}=6.7 \times 10^{7} \mathrm{~N} / \mathrm{m}$

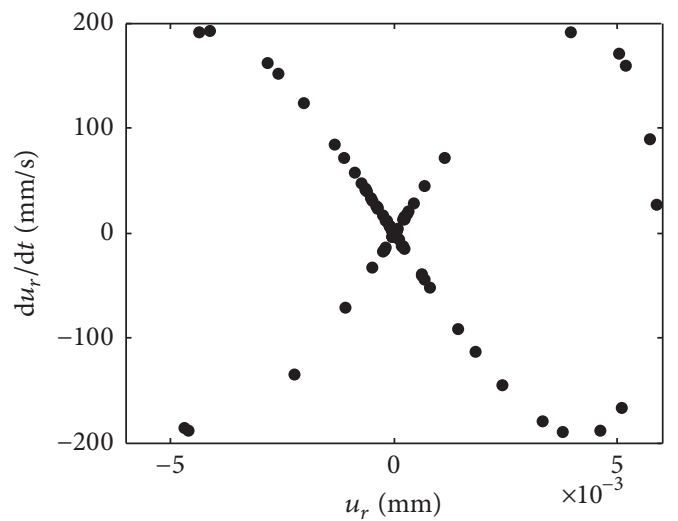

(f) $k_{p \text {-av }}=4 \times 10^{7} \mathrm{~N} / \mathrm{m}$

FIgURE 6: Poincare map of torsional vibration response for different average mesh stiffness.

Poincare map of the torsional vibration of movable tooth drive system can be obtained. Figure 7 shows power spectrum of torsional vibration response for different average mesh stiffness. Power spectrum shows changes of the signal power along with exciting frequency from which chaotic motion can be determined. Here, periodogram method is used to calculate power spectrum of the vibration. From Figures 6 and 7 , the following are known.

(1) As the average mesh stiffness changes, the vibration displacements of central elements change. At $k_{s \text {-av }}=1 \times$
$10^{7} \mathrm{~N} / \mathrm{m}, 3.8 \times 10^{7} \mathrm{~N} / \mathrm{m}, k_{c \text {-av }}=6 \times 10^{3} \mathrm{~N} / \mathrm{m}, 6.7 \times 10^{7} \mathrm{~N} / \mathrm{m}$, and $k_{p \text {-av }}=2 \times 10^{3} \mathrm{~N} / \mathrm{m}, 4 \times 10^{7} \mathrm{~N} / \mathrm{m}$, jumping of the vibration displacement of central elements occurs. Here, a small change of the average mesh stiffness can cause significant change of the vibration displacements. It causes unstable vibration of the movable tooth drive system.

(2) At $k_{s \text {-av }}=1 \times 10^{7} \mathrm{~N} / \mathrm{m}, 3.8 \times 10^{7} \mathrm{~N} / \mathrm{m}, k_{c \text {-av }}=6 \times$ $10^{3} \mathrm{~N} / \mathrm{m}, 6.7 \times 10^{7} \mathrm{~N} / \mathrm{m}$, and $k_{p \text {-av }}=2 \times 10^{3} \mathrm{~N} / \mathrm{m}, 4 \times 10^{7} \mathrm{~N} / \mathrm{m}$, a distributed point set with a certain geometry appears on the Poincare map, the power spectra become continuous. It 


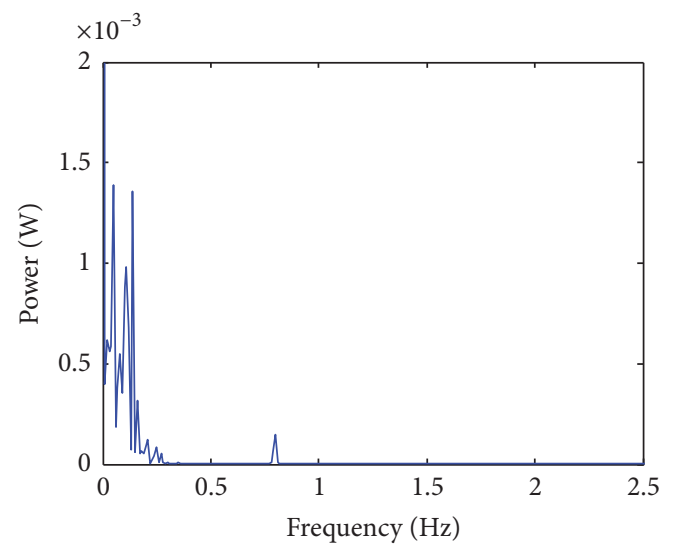

(a) $k_{s \text {-av }}=1 \times 10^{7} \mathrm{~N} / \mathrm{m}$

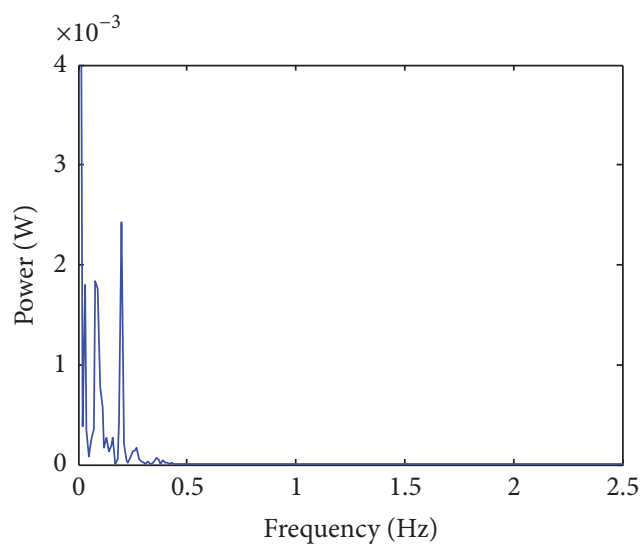

(c) $k_{c \text {-av }}=6 \times 10^{3} \mathrm{~N} / \mathrm{m}$

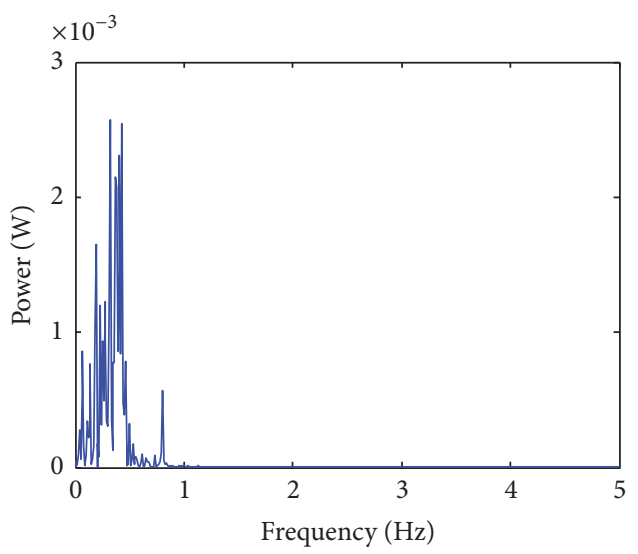

(e) $k_{p \text {-av }}=2 \times 10^{3} \mathrm{~N} / \mathrm{m}$

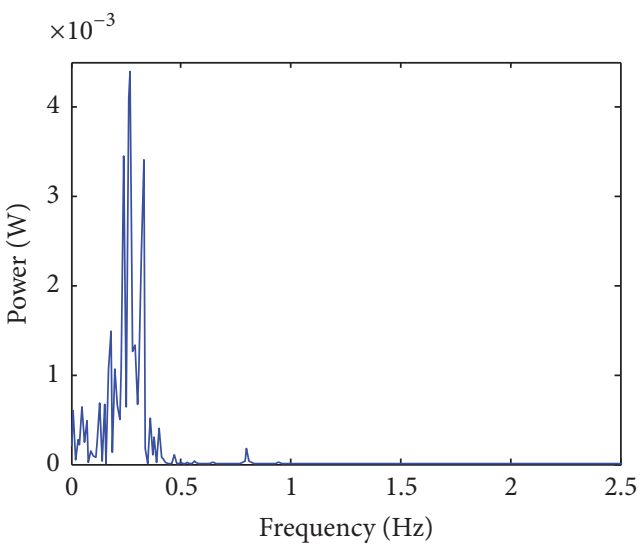

(b) $k_{s-\mathrm{av}}=3.8 \times 10^{7} \mathrm{~N} / \mathrm{m}$

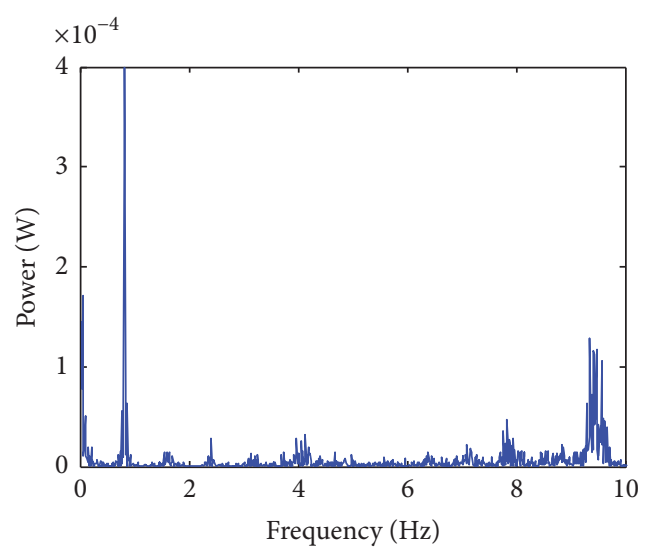

(d) $k_{c \text {-av }}=6.7 \times 10^{7} \mathrm{~N} / \mathrm{m}$

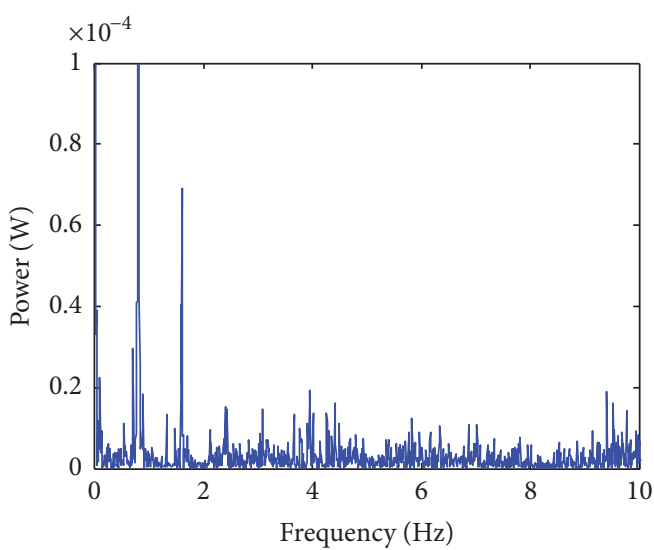

(f) $k_{p \text {-av }}=4 \times 10^{7} \mathrm{~N} / \mathrm{m}$

FIgURE 7: Power spectrum of torsional vibration response for different average mesh stiffness.

shows that chaotic vibration occurs in piezoelectric actuator. Meanwhile, At above average mesh stiffness points, the vibration displacements of the central elements are larger than those for other average mesh stiffness. Among them, the vibration displacement of the movable tooth drive system is the larger at $k_{s-\text { av }}=3.8 \times 10^{7} \mathrm{~N} / \mathrm{m}$ and $k_{p \text {-av }}=2 \times 10^{3} \mathrm{~N} / \mathrm{m}$.

(3) The chaotic vibration of movable tooth drive system occurs when average mesh stiffness $k_{j \text {-av }}$ exceeds a specific value. Moreover, the starting point of chaotic vibration is different for each central element. When $k_{p \text {-av }}$ is very small, the chaotic vibration of rotor occurs, but the chaotic vibration of wave generator occurs only when $k_{p \text {-av }}$ increases larger.

In general, from chaotic vibration theory, it is known that break of quasiperiodic torus is the main reason leading to the chaotic vibration of the drive system. In addition, the chaotic vibration is sensitive for the small change of main parameters. Sometimes, the chaotic vibration only occurs in a moment. Hence, the average mesh stiffness is the primary parameter 


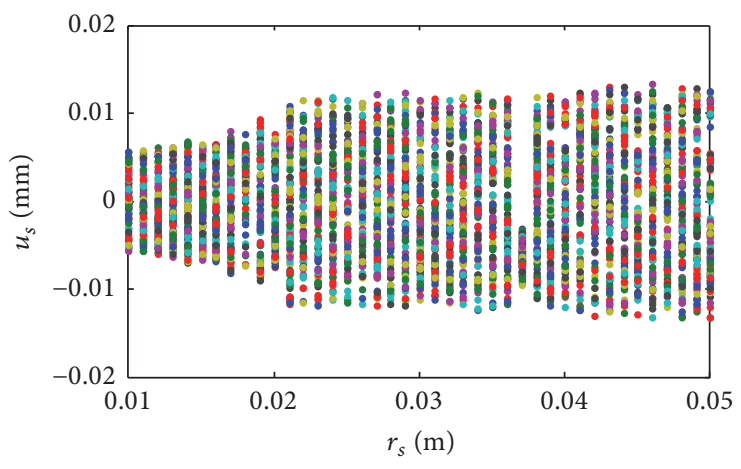

(a) $r_{s}=10 \sim 50 \mathrm{~mm}$

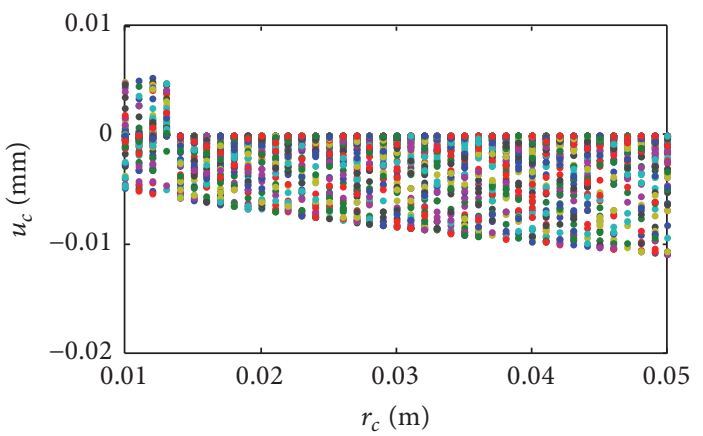

(c) $r_{c}=10 \sim 50 \mathrm{~mm}$

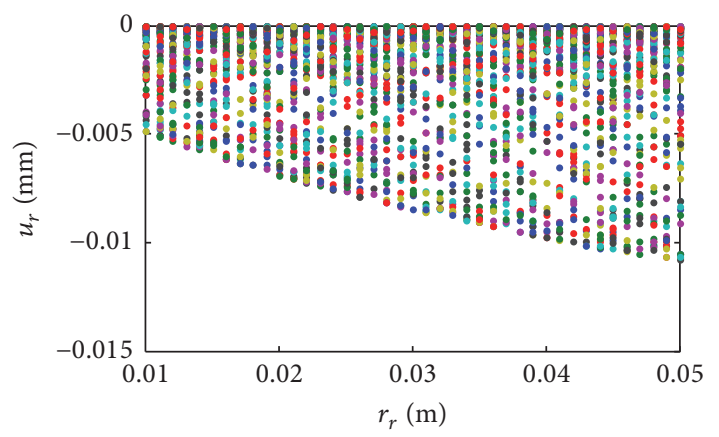

(e) $r_{r}=10 \sim 50 \mathrm{~mm}$

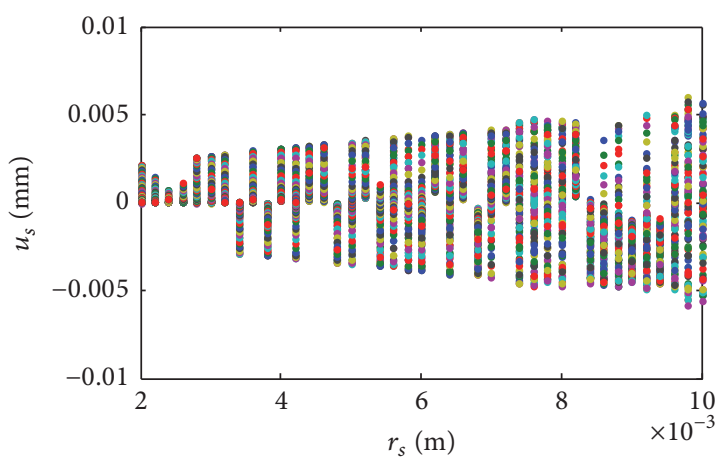

(b) $r_{s}=2 \sim 10 \mathrm{~mm}$

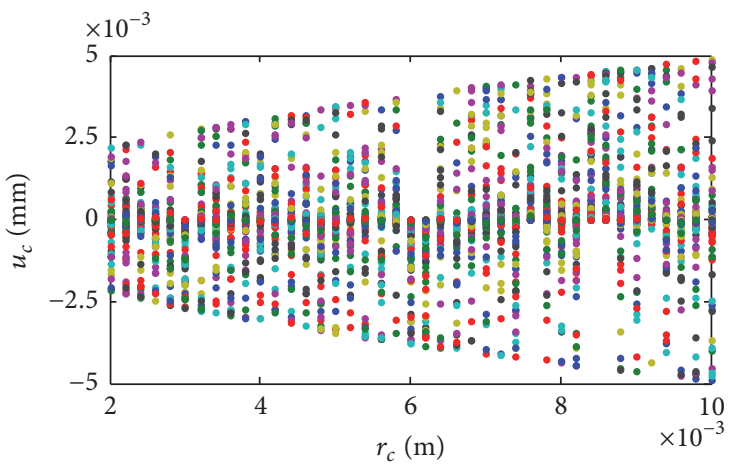

(d) $r_{c}=2 \sim 10 \mathrm{~mm}$

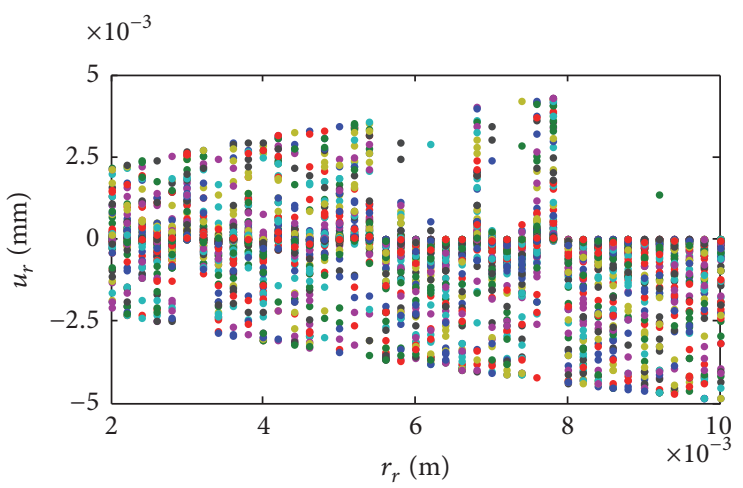

(f) $r_{r}=2 \sim 10 \mathrm{~mm}$

FIGURE 8: Bifurcation with theoretical radius.

that affects the chaotic vibration of the piezoelectric motor. To obtain a good dynamic performance, the average mesh stiffness should be selected properly.

3.2. Influence of Theoretical Radius on Chaotic Vibration. Figure 8 gives bifurcation diagrams of torsional vibration of movable tooth drive system for theoretical radius $r_{j}$ varying from $10 \mathrm{~mm}$ to $50 \mathrm{~mm}$. Here, the Poincare section method is utilized to obtain the bifurcation diagrams. Changing radius $r_{j}$ from $10 \mathrm{~mm}$ to $50 \mathrm{~mm}$, one Poincare map is calculated for each theoretical radius. Based on it, the bifurcation diagram of torsional vibration for theoretical radius is given. From Figure 8, the following are known.

(1) In bifurcation diagram of wave generator, sudden change of vibration displacement occurs at $r_{s}=3.8 \mathrm{~mm}$, and intermittent sudden changes happen during $r_{s}=3.8 \sim 10 \mathrm{~mm}$. However, the maximum vibration displacement increases steadily when $r_{s}>10 \mathrm{~mm}$.

(2) In bifurcation diagram of rigid cog, when $r_{c}=14 \mathrm{~mm}$, major jump change of vibration displacement appears, and small jump change occurs at $r_{c}=6 \mathrm{~mm}$. Besides, the vibration displacement increases stability when $r_{c}>14 \mathrm{~mm}$.

(3) In bifurcation diagram of rotor, it is similar to rigid $\operatorname{cog}$. The difference is that the major sudden change of vibration displacement of rotor occurs at $r_{r}=8 \mathrm{~mm}$, earlier than $r_{c}=14 \mathrm{~mm}$; moreover, the number of small jump changes increases when $r_{r}<8 \mathrm{~mm}$.

(4) Compared with rigid cog and rotor, the displacement sudden change of wave generator happens when theoretical radius is quite small. Hence, the chaotic vibration of wave 


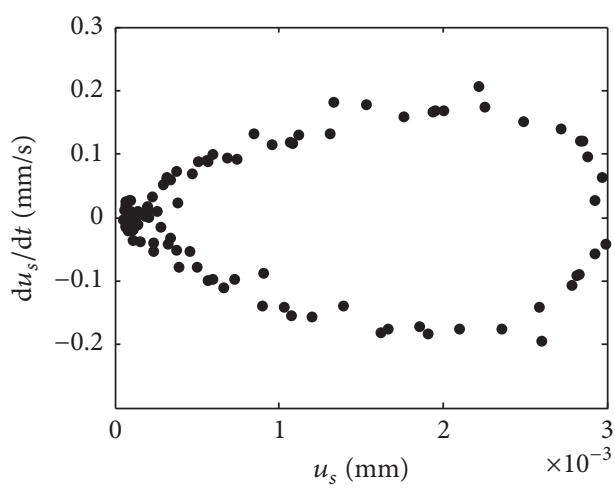

(a) $r_{s}=3.7 \mathrm{~mm}$

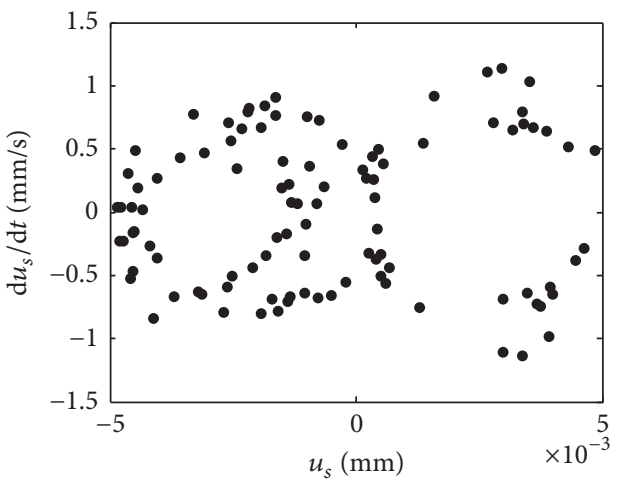

(c) $r_{s}=9 \mathrm{~mm}$

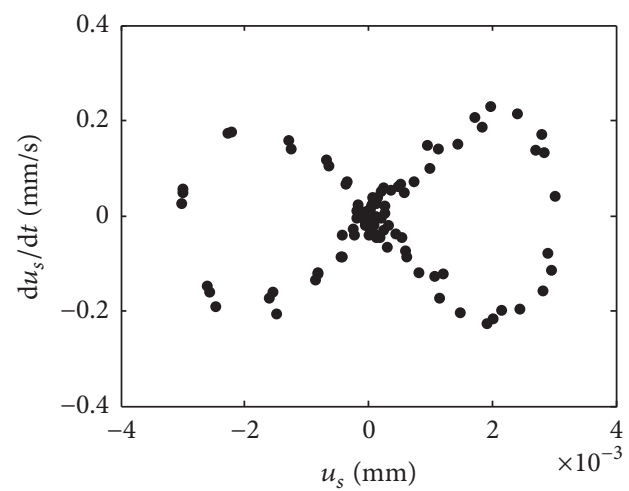

(b) $r_{s}=3.8 \mathrm{~mm}$

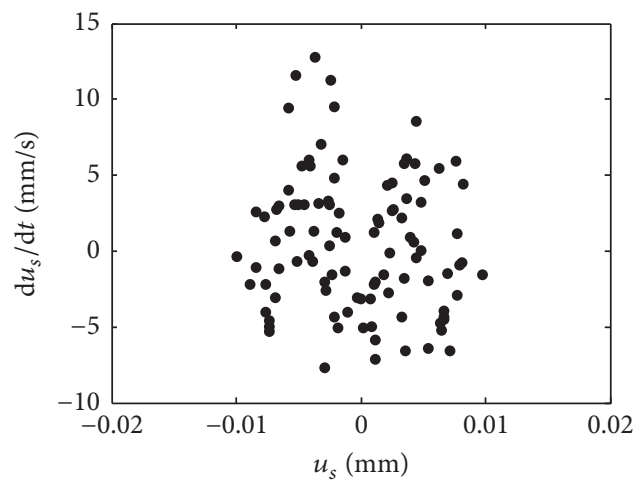

(d) $r_{s}=20 \mathrm{~mm}$

FIGURE 9: Poincare map of vibration response of wave generator for different theoretical radius.

generator tends to take place earlier than rigid cog and rotor. The reason is that the external forces apply on the wave generator. The wave generator is easier to generate vibration. So, in order to obtain a good performance of the piezoelectric motor, the vibration of wave generator should be suppressed.

Figures 9 and 10, Figures 11 and 12, and Figures 13 and 14 show Poincare map and power spectrum of vibration response of wave generator, rigid cog, and rotor for different theoretical radius. From Figures 9-14, the following are known.

(1) At $r_{s}=3.7 \mathrm{~mm}$, a distributed point set with a ring structure appears on the Poincare map of wave generator, and the power spectra becomes discrete. This shows that the wave generator exhibits a quasiperiod vibration. However, at $r_{s}=3.8 \mathrm{~mm}$, the power spectra become continuous. It is shown that chaotic vibration occurs in wave generator, and $r_{s}=3.8 \mathrm{~mm}$ becomes a demarcation point from quasiperiod vibration to chaotic vibration. Similarly, at $r_{s}=9 \mathrm{~mm}$ or $20 \mathrm{~mm}$, the wave generator shows quasiperiod vibrations.

(2) At $r_{c}=5.5 \mathrm{~mm}$, a distributed point set with a certain geometry appears on the Poincare map of rigid cog; the power spectra appear to be continuous. It is shown that chaotic vibration occurs in rigid cog. However, at $r_{c}=6 \mathrm{~mm}$, the power spectra turn into continuous, so the rigid cog changes into quasiperiod vibration. By the same token, at $r_{c}=13 \mathrm{~mm}$ and $14 \mathrm{~mm}$, the rigid cog appears to be chaotic vibration and quasiperiod vibration, respectively. Besides, the power spectra at $r_{c}>14 \mathrm{~mm}$ and $r_{c}=6 \mathrm{~mm}$ and $14 \mathrm{~mm}$ are similar. This shows that the chaotic vibration disappears when $r_{c}>$ $14 \mathrm{~mm}$.

(3) The law of vibration response of rotor is similar to rigid cog. At $r_{r}=5.2 \mathrm{~mm}$ and $7.8 \mathrm{~mm}$, the system exhibits chaotic vibration. And at $r_{r}=5.4 \mathrm{~mm}$ and $8 \mathrm{~mm}$, the quasiperiod vibration is shown in rotor. Similarly, the chaotic vibration disappears when $r_{r}>8 \mathrm{~mm}$.

In general, the chaotic vibration sudden change occurs when theoretical radius takes some certain value. From chaotic vibration theory, the phenomenon that chaos attractors suddenly appear or disappear is interior crisis or boundary crisis. The reason for generating of the two-type crisis is that the collision between chaos attractors and unstable period occurs at interior and boundary of attraction basin. Therefore, when theoretical radius changes, the way to chaotic vibration is paroxysmal.

3.3. Influence of Wave Generator Offset on Chaotic Vibration. Figure 15 gives bifurcation diagrams of torsional vibration of movable tooth drive system for wave generator offset $a$ varying from 0 to $1 \mathrm{~mm}$. Figures $16-18$ show power spectrum and time response of wave generator, rigid cog, and rotor for different wave generator offset. From Figures 15-18, the following are known.

(1) At $a=0$, the vibration displacement of wave generator is very small from bifurcation diagram and time response 


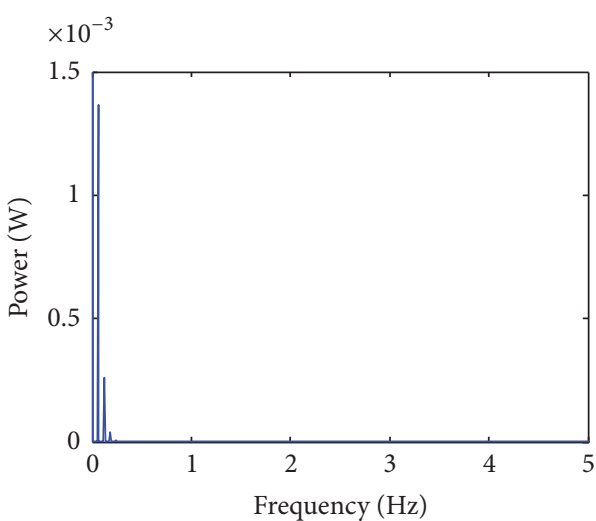

(a) $r_{s}=3.7 \mathrm{~mm}$

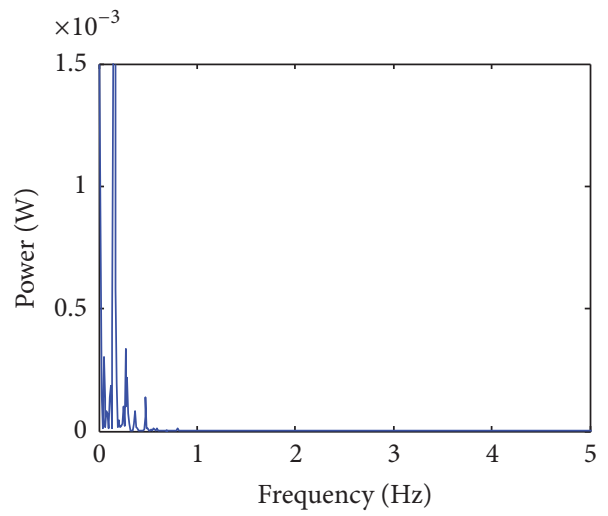

(c) $r_{s}=9 \mathrm{~mm}$

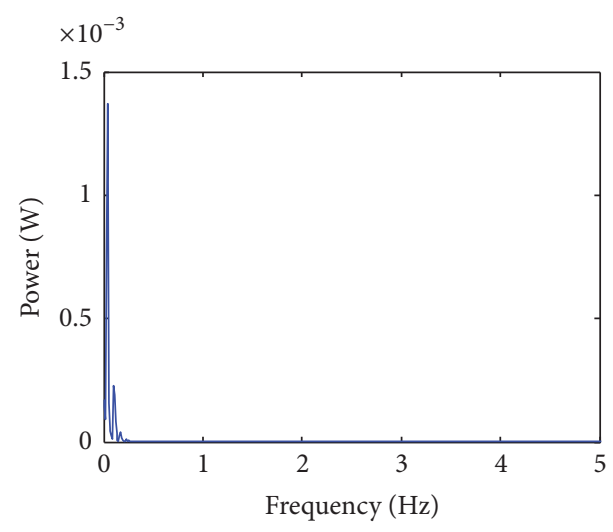

(b) $r_{s}=3.8 \mathrm{~mm}$

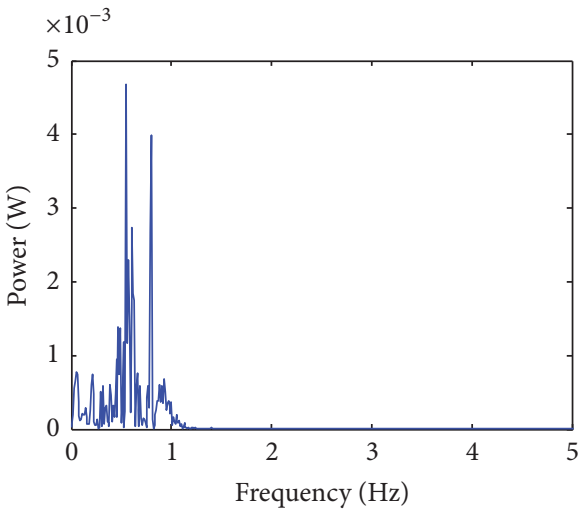

(d) $r_{s}=20 \mathrm{~mm}$

FIGURE 10: Power spectrum of vibration response of wave generator for different theoretical radius.

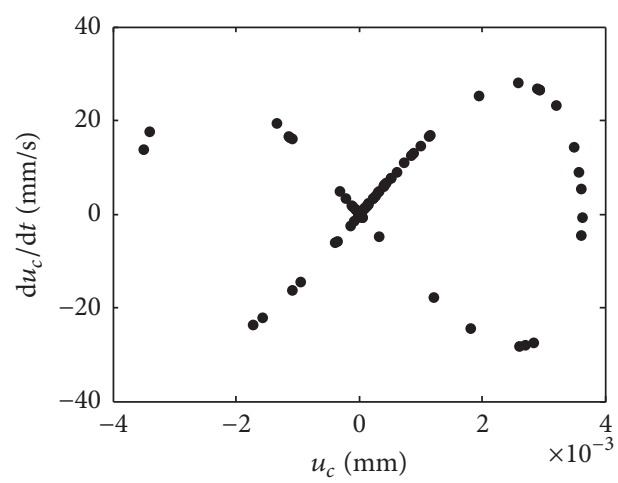

(a) $r_{c}=5.5 \mathrm{~mm}$

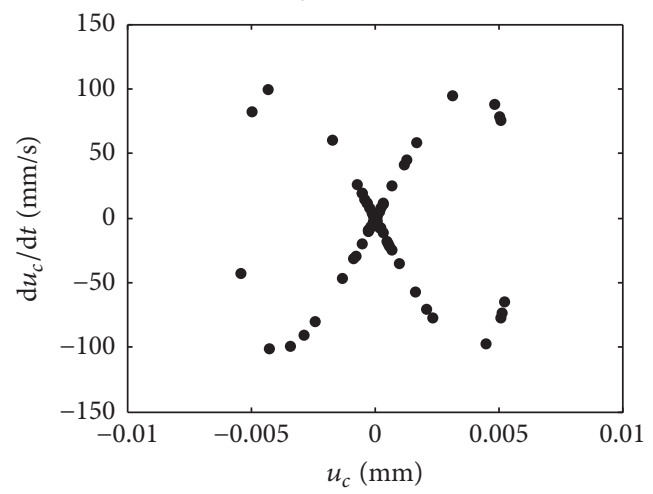

(c) $r_{c}=13 \mathrm{~mm}$

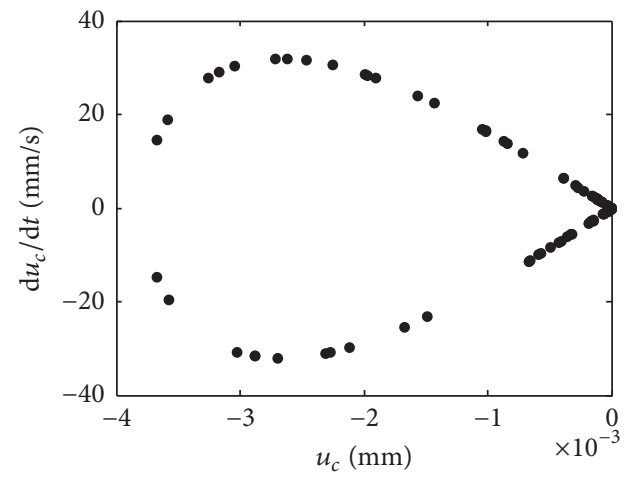

(b) $r_{c}=6 \mathrm{~mm}$

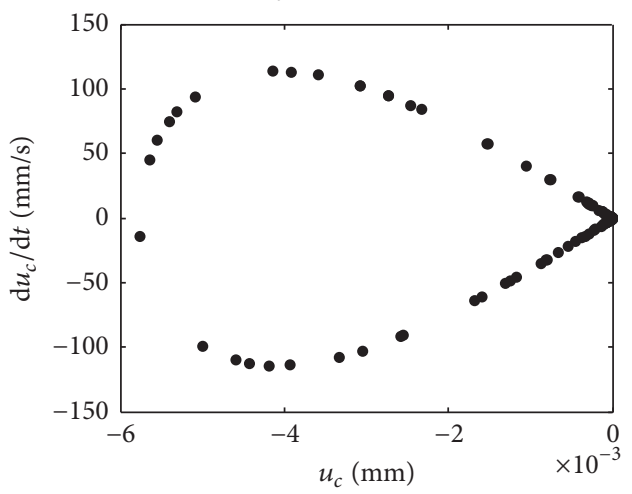

(d) $r_{c}=14 \mathrm{~mm}$

FIGURE 11: Poincare map of vibration response of rigid cog for different theoretical radius. 

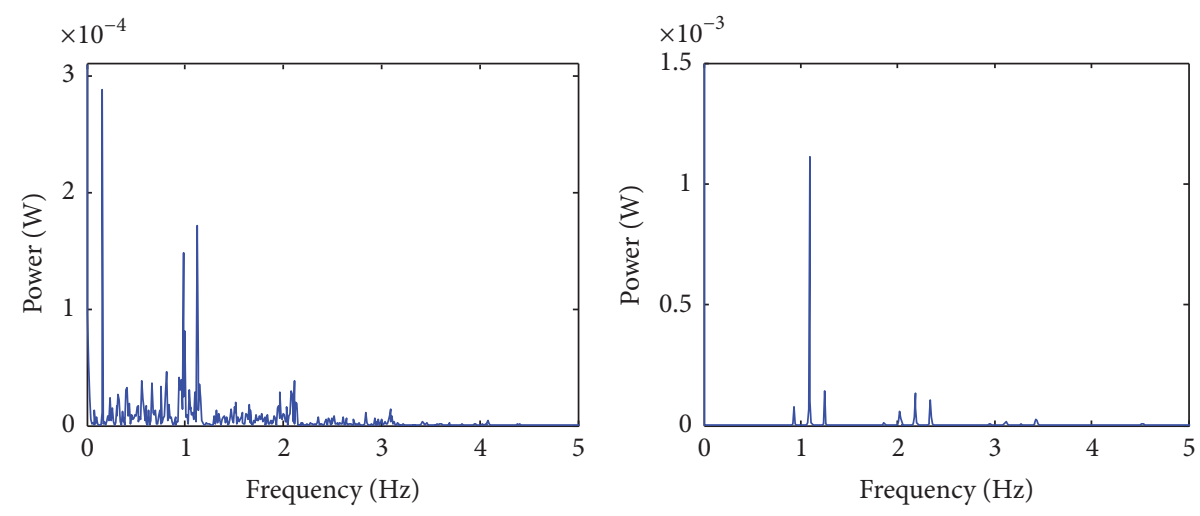

(a) $r_{c}=5.5 \mathrm{~mm}$

(b) $r_{c}=6 \mathrm{~mm}$
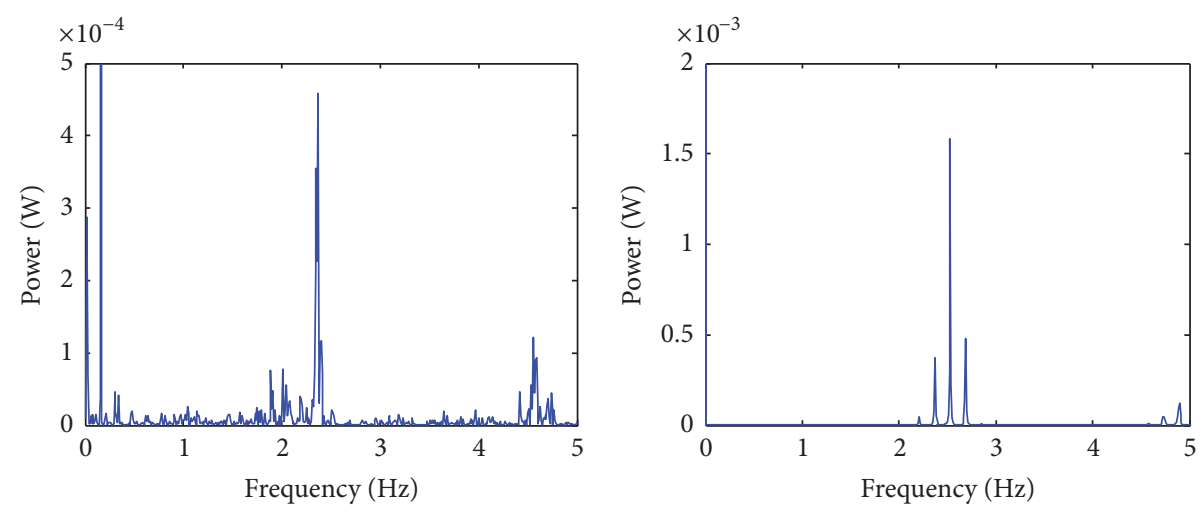

(c) $r_{c}=13 \mathrm{~mm}$

(d) $r_{c}=14 \mathrm{~mm}$

FIGURE 12: Power spectrum of vibration response of rigid cog for different theoretical radius.

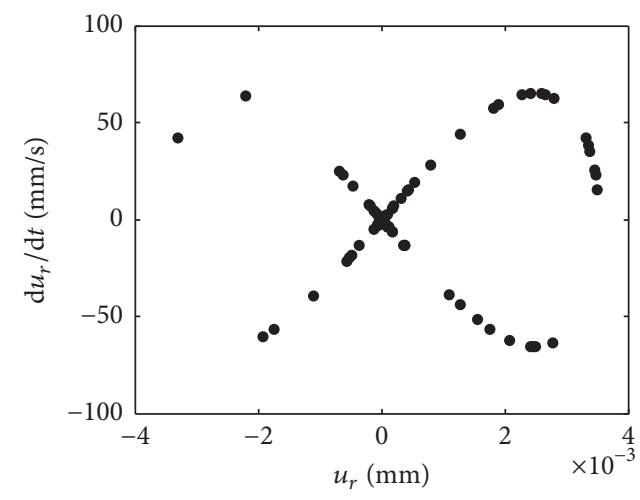

(a) $r_{r}=5.2 \mathrm{~mm}$

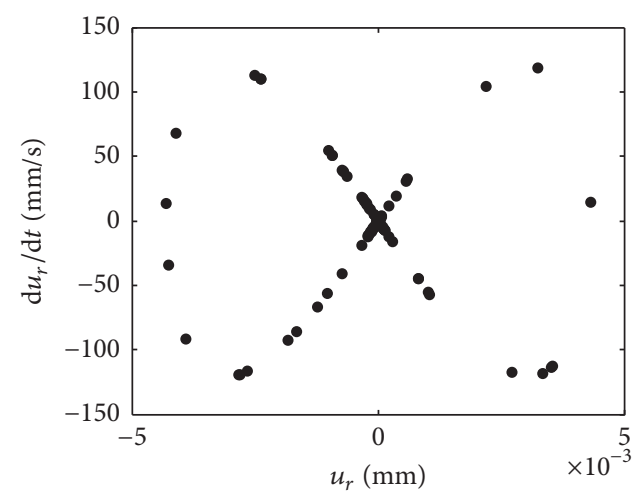

(c) $r_{r}=7.8 \mathrm{~mm}$

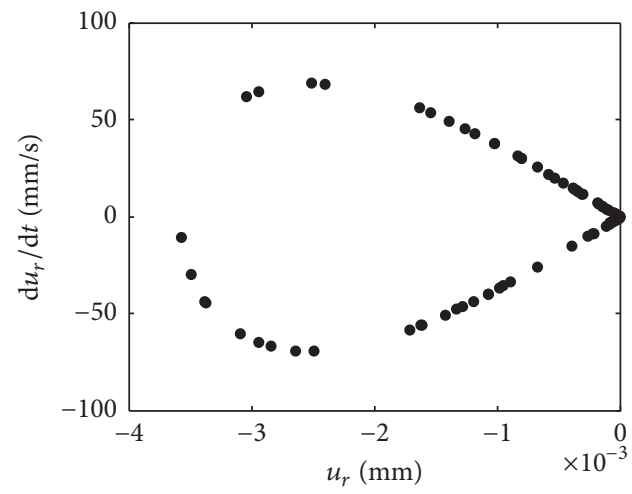

(b) $r_{r}=5.4 \mathrm{~mm}$

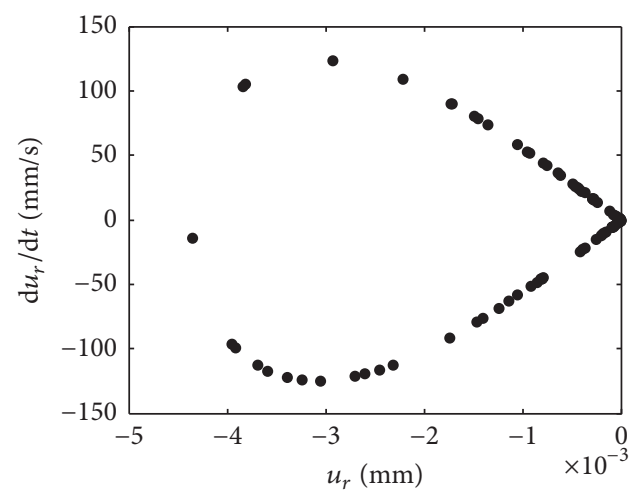

(d) $r_{r}=8 \mathrm{~mm}$

FIgURE 13: Poincare map of vibration response of rotor for different theoretical radius. 


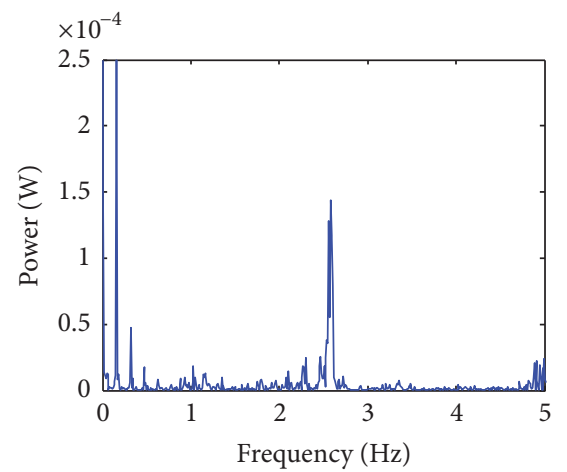

(a) $r_{r}=5.2 \mathrm{~mm}$

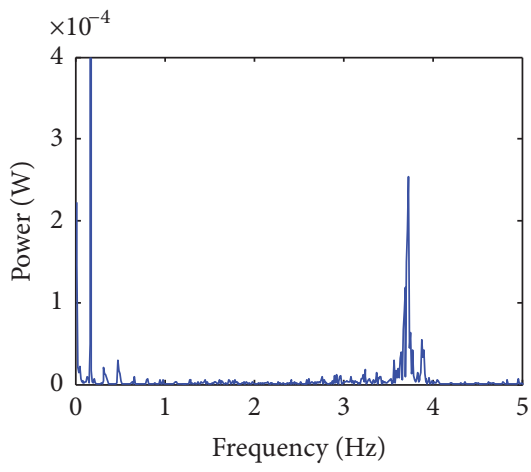

(c) $r_{r}=7.8 \mathrm{~mm}$

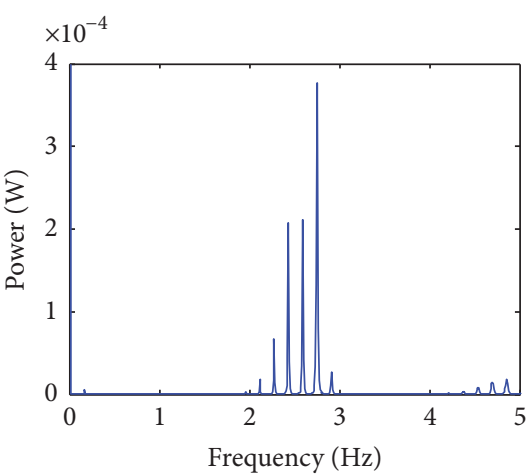

(b) $r_{r}=5.4 \mathrm{~mm}$

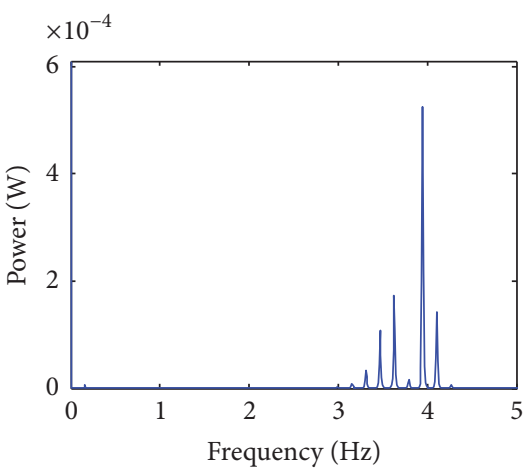

(d) $r_{r}=8 \mathrm{~mm}$

FIgURE 14: Power spectrum of vibration response of rotor for different theoretical radius.

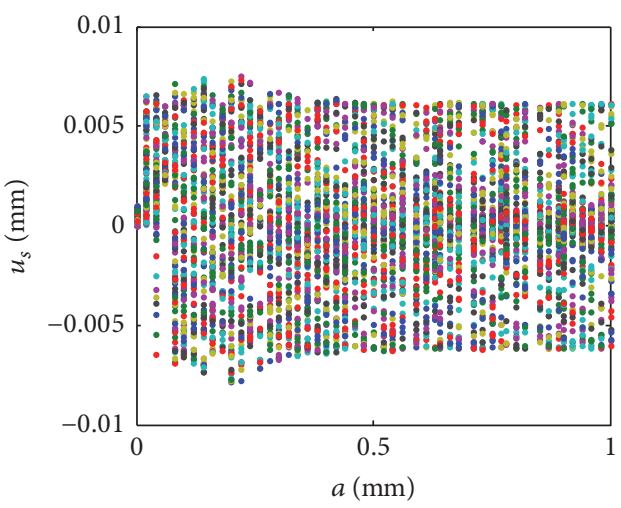

(a) Wave generator $(a=0 \sim 1 \mathrm{~mm})$

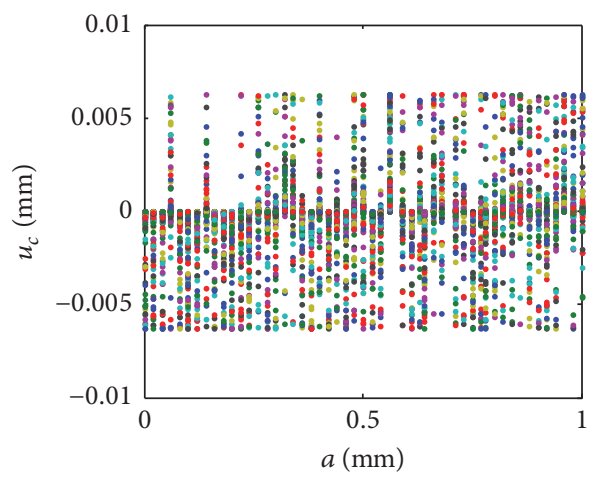

(c) Rigid $\operatorname{cog}(a=0 \sim 1 \mathrm{~mm})$

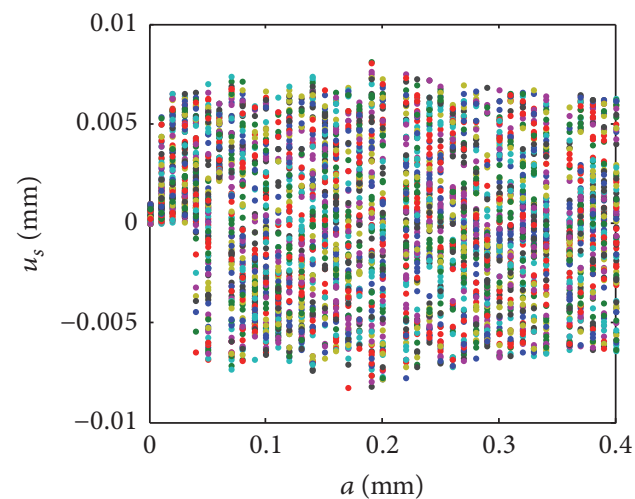

(b) Wave generator $(a=0 \sim 0.4 \mathrm{~mm})$

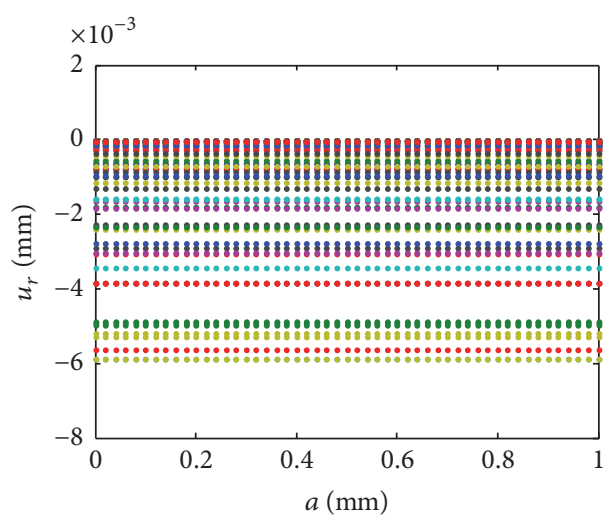

(d) Rotor $(a=0 \sim 1 \mathrm{~mm})$

FIGURE 15: Bifurcation with wave generator offset. 


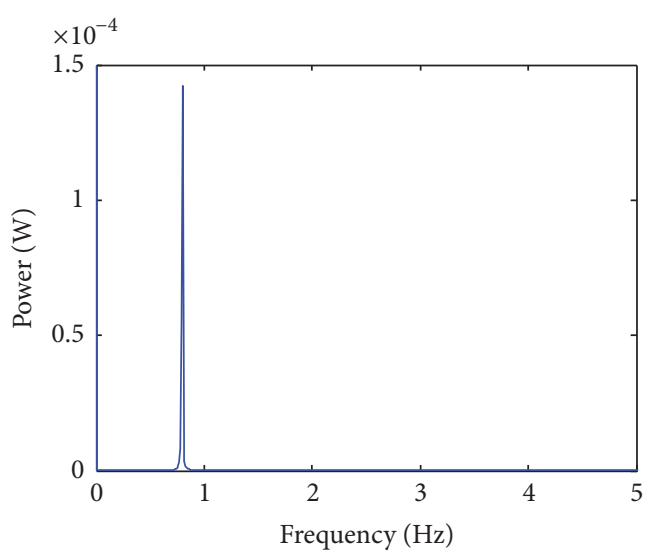

(a) Power spectrum for $a=0$

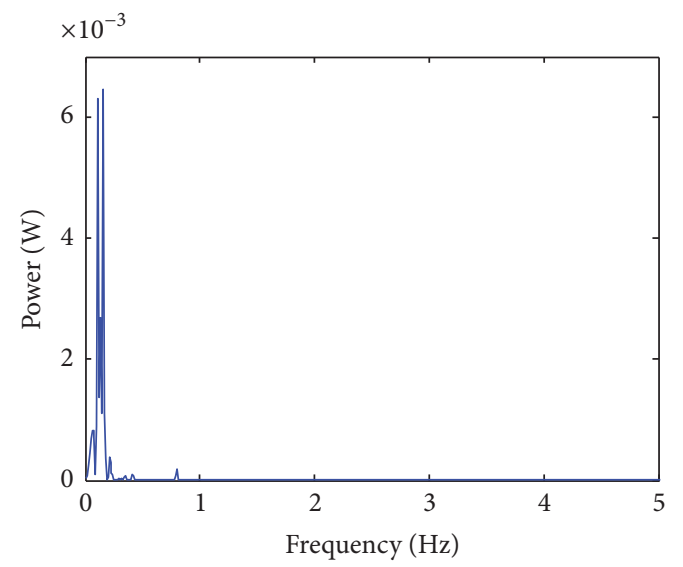

(c) Power spectrum for $a=0.04 \mathrm{~mm}$

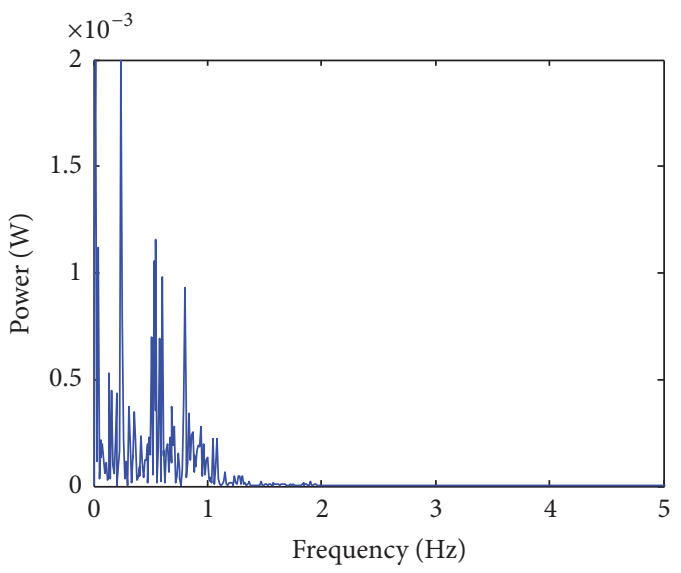

(e) Power spectrum for $a=0.2 \mathrm{~mm}$

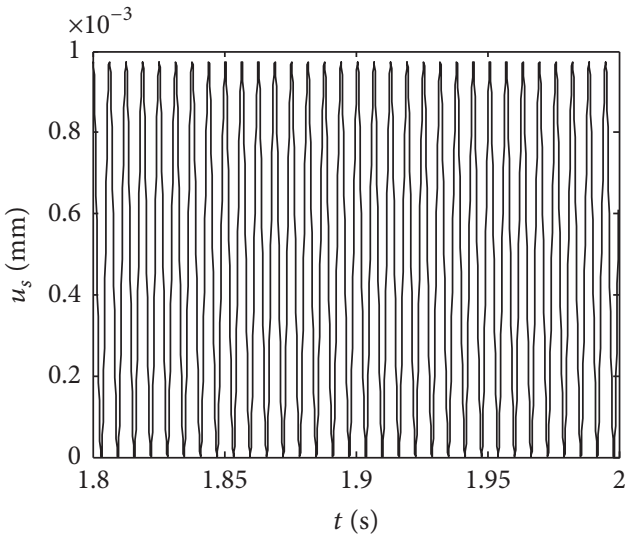

(b) Time response for $a=0$

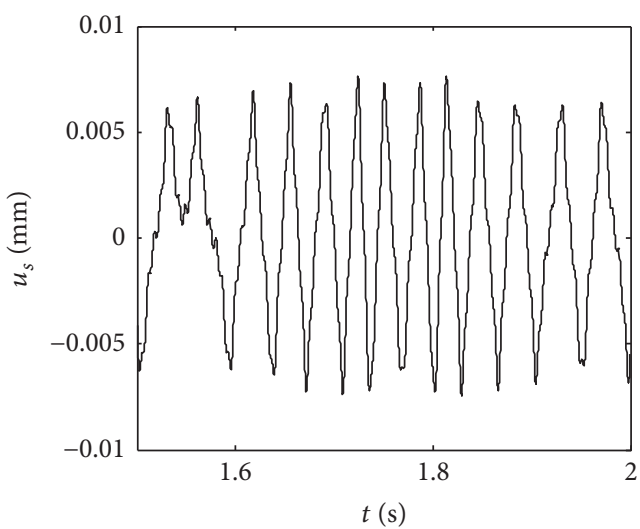

(d) Time response for $a=0.04 \mathrm{~mm}$

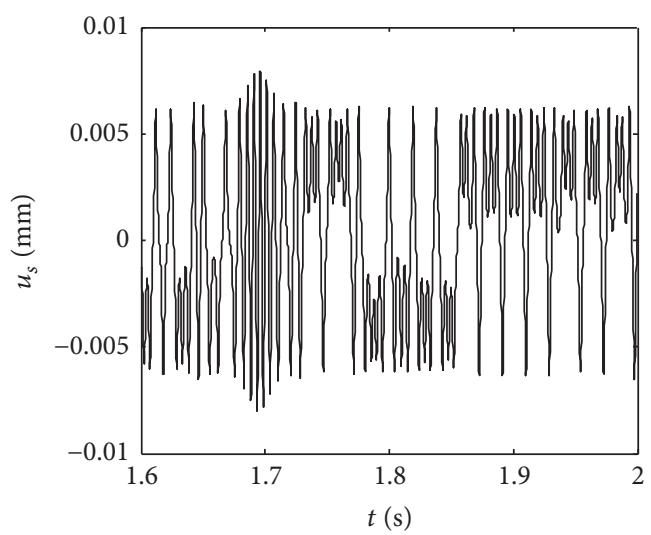

(f) Time response for $a=0.2 \mathrm{~mm}$

FIGURE 16: Power spectrum and time response of wave generator for different wave generator offset.

graph, and a single discrete peak appears in power spectrum. This shows that wave generator exhibits a period-one vibration. At $a=0.04 \mathrm{~mm}$, a sudden change appears in bifurcation diagram, aperiodic amplitude jumping vibrations occur on the time response of wave generator, and power spectrum becomes continuous. It is shown that the chaotic vibration takes place on wave generator. However, displacement of chaotic vibration behaves invariably when $a>0.3 \mathrm{~mm}$.
(2) At $a=0,0.06 \mathrm{~mm}$ and $0.16 \mathrm{~mm}$, sudden changes occur in bifurcation diagram of rigid cog. The power spectrum behaves continuously, and the time response appears aperiodic. It shows that initial stage chaotic vibration occurs on rigid cog. For the length ranges of $[(0,0.06),(0.06,0.16)]$, the stable quasiperiod vibration of rigid cog occurs.

(3) From Figure 15(d), vibration displacement of rotor does not change with $a$. At $a=0$ and $0.1 \mathrm{~mm}$, the rotor 


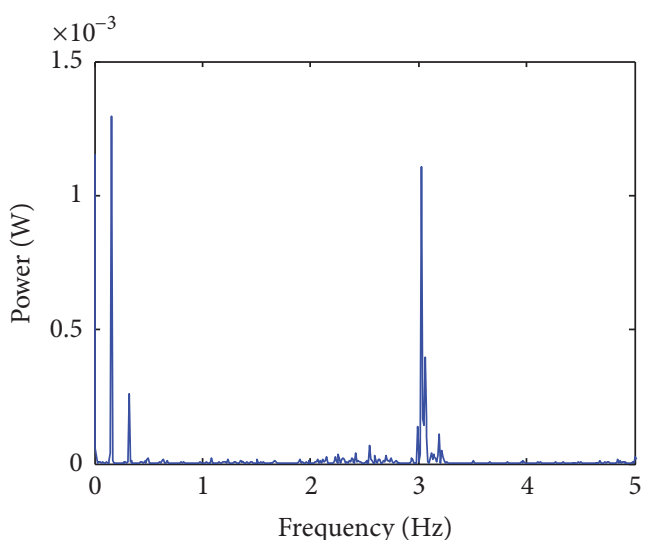

(a) Power spectrum for $a=0$

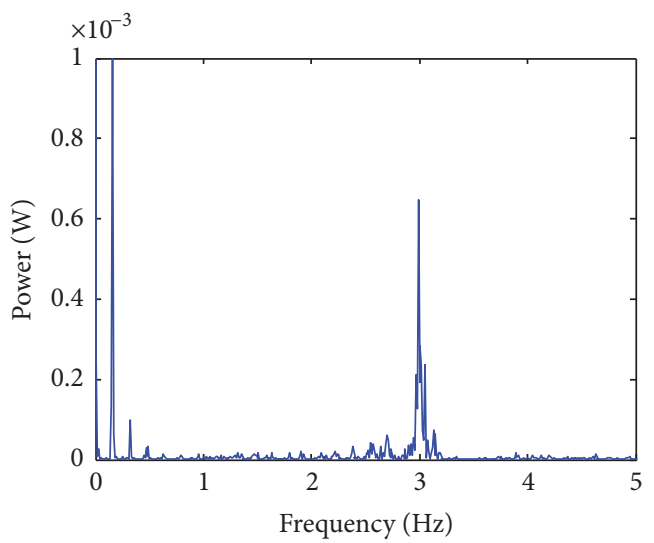

(c) Power spectrum for $a=0.06 \mathrm{~mm}$

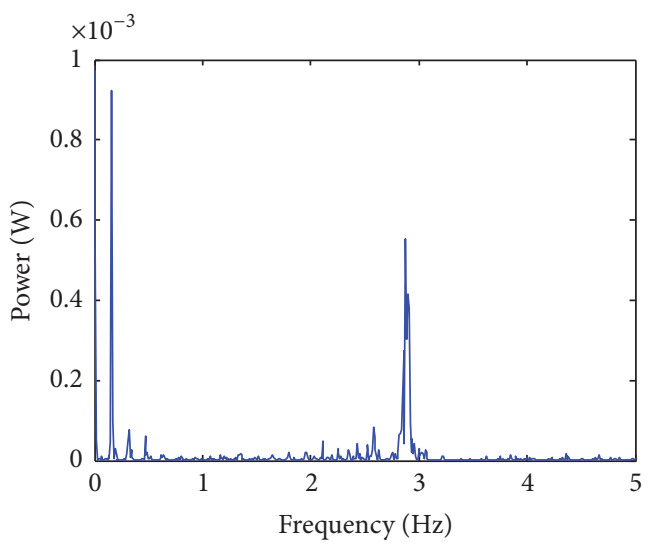

(e) Power spectrum for $a=0.16 \mathrm{~mm}$

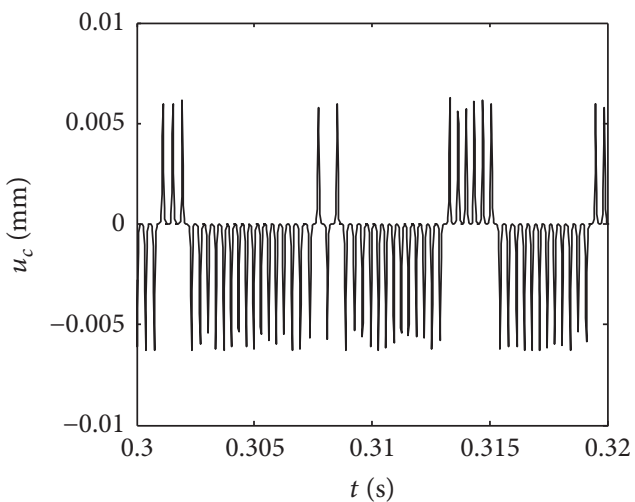

(b) Time response for $a=0$

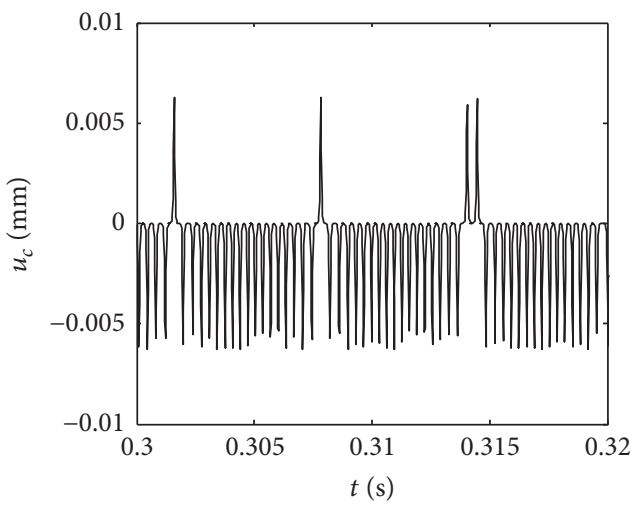

(d) Time response for $a=0.06 \mathrm{~mm}$

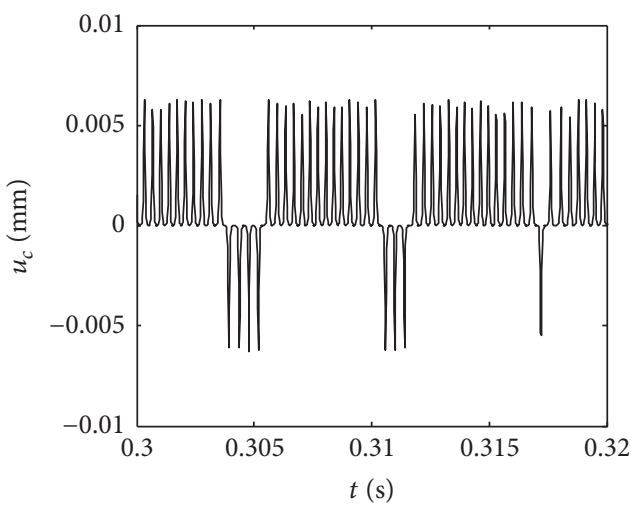

(f) Time response for $a=0.16 \mathrm{~mm}$

FIGURE 17: Power spectrum and time response of rigid cog for different wave generator offset.

exhibits quasiperiod vibration accompanied with chaotic vibration.

In short, from chaotic vibration theory, the main way to chaotic vibration is paroxysmal. But for the rotor, break of quasiperiodic torus is another reason for the chaotic vibration. Hence, wave generator offset $a$ has also a significant influence on the chaotic vibration of the movable tooth drive system. To obtain a good performance of the piezoelectric motor, the wave generator offset should be chosen properly as well.

\section{Conclusions}

In this paper, the nonlinear dynamic performance and chaotic vibration of transmission system for movable tooth piezoelectric motor are investigated. The results show the following.

(1) The average mesh stiffness has an significant influence on the chaotic vibration of the transmission system. At $k_{s \text {-av }}=$ $1 \times 10^{7} \mathrm{~N} / \mathrm{m}, 3.8 \times 10^{7} \mathrm{~N} / \mathrm{m}, k_{c \text {-av }}=6 \times 10^{3} \mathrm{~N} / \mathrm{m}, 6.7 \times$ $10^{7} \mathrm{~N} / \mathrm{m}$, and $k_{p \text {-av }}=2 \times 10^{3} \mathrm{~N} / \mathrm{m}, 4 \times 10^{7} \mathrm{~N} / \mathrm{m}$, the chaotic 


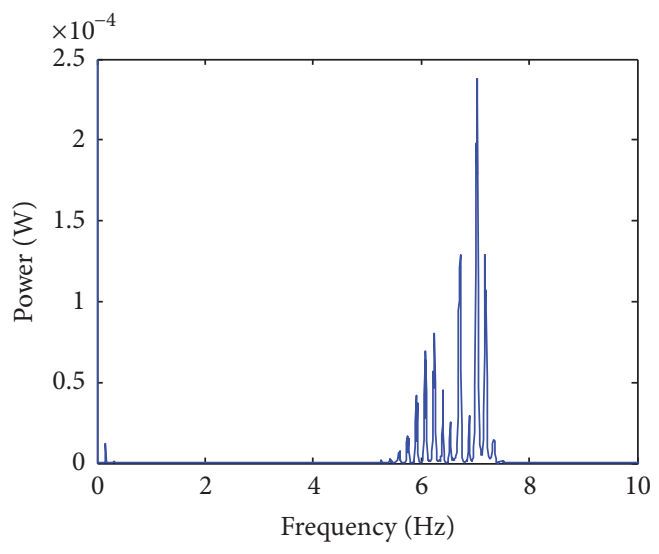

(a) Power spectrum for $a=0$

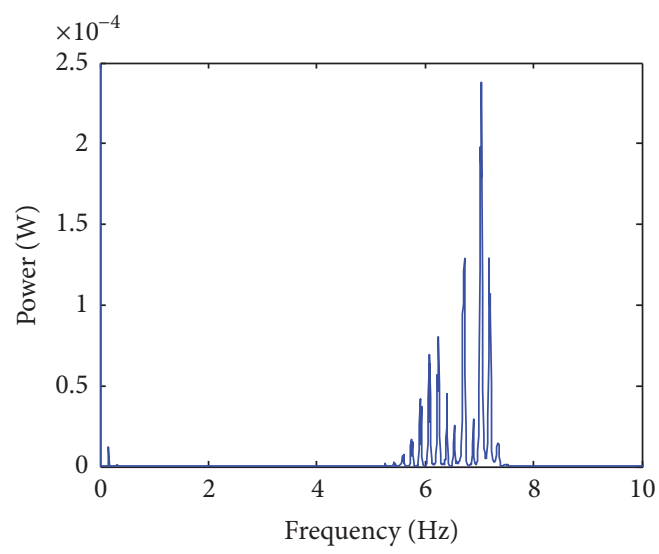

(c) Power spectrum for $a=0.1 \mathrm{~mm}$

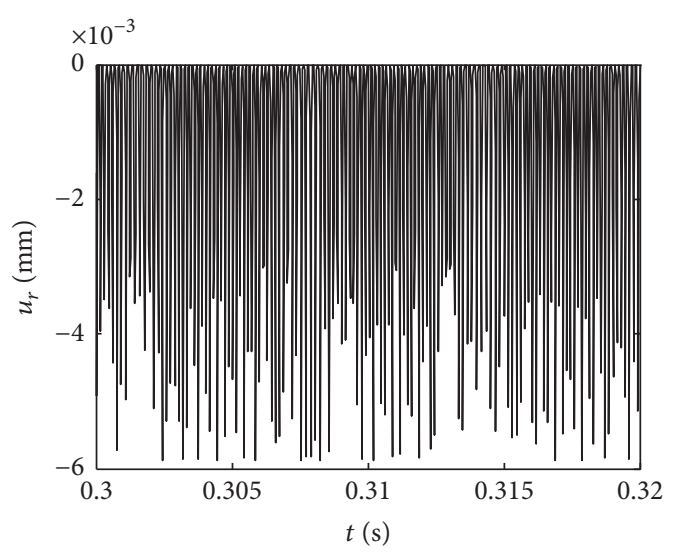

(b) Time response for $a=0$

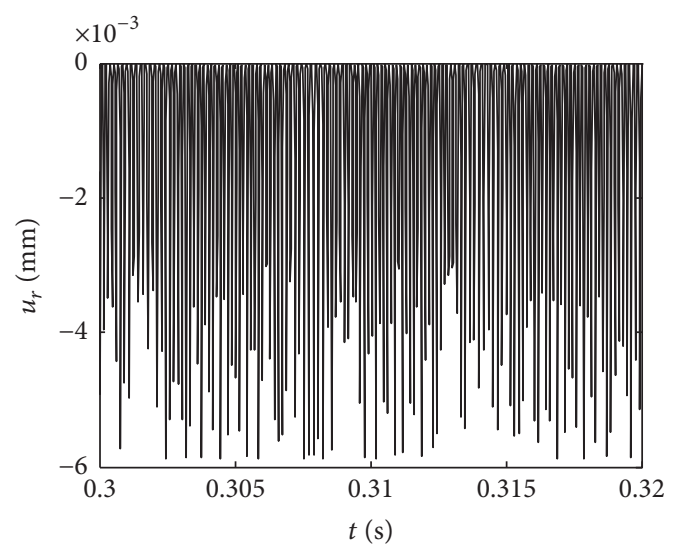

(d) Time response for $a=0.1 \mathrm{~mm}$

FIGURE 18: Power spectrum and time response of rotor for different wave generator offset.

vibration occurs in the transmission system of the motor.

(2) As theoretical radius changes, the wave generator exhibits chaotic vibration when $r_{s}$ is quite small.

(3) The influence of wave generator offset $a$ on chaotic vibration of wave generator is most obvious.

\section{Conflicts of Interest}

The authors declare that there are no conflicts of interest regarding the publication of this paper.

\section{Acknowledgments}

This project is supported by National Natural Science Foundation of China (51605423) and Doctoral Scientific Research Foundation of Jiangsu University of Science and Technology (1022931704).

\section{References}

[1] W. Wu, C. Pan, Y. Zhang, X. Wen, and Z. L. Wang, "Piezotronics and piezo-phototronics-from single nanodevices to array of devices and then to integrated functional system," Nano Today, vol. 8, no. 6, pp. 619-642, 2013.
[2] C.-Y. Lin and C.-Y. Li, "A neural-repetitive control approach for high-performance motion control of piezo-actuated systems," Arabian Journal for Science and Engineering, vol. 39, no. 5, pp. 4131-4140, 2014.

[3] W.-A. Jiang, L.-Q. Chen, and H. Ding, "Internal resonance in axially loaded beam energy harvesters with an oscillator to enhance the bandwidth," Nonlinear Dynamics, vol. 85, no. 4, pp. 2507-2520, 2016.

[4] M. Kurosawa, K. Nakamura, T. Okamoto, and S. Ueha, "An ultrasonic motor using bending vibrations of a short cylinder," IEEE Transactions on Ultrasonics, Ferroelectrics, and Frequency Control, vol. 36, no. 5, pp. 517-521, 1989.

[5] B. Koc, S. Cagatay, and K. Uchino, "A piezoelectric motor using two orthogonal bending modes of a hollow cylinder," IEEE Transactions on Ultrasonics, Ferroelectrics, and Frequency Control, vol. 49, no. 4, pp. 495-500, 2002.

[6] T. Mashimo, "Micro ultrasonic motor using a one cubic millimeter stator," Sensors and Actuators, A: Physical, vol. 213, no. 7, pp. 102-107, 2014.

[7] R. B. Mrad, A. Abhari, and J. Zu, "A control methodology for an inchworm piezomotor," Mechanical Systems and Signal Processing, vol. 17, no. 2, pp. 457-471, 2003.

[8] C.-H. Oh, J.-H. Choi, H.-J. Nam, J.-U. Bu, and S.-H. Kim, "Ultracompact, zero-power magnetic latching piezoelectric inchworm motor with integrated position sensor," Sensors and Actuators A: Physical, vol. 158, no. 2, pp. 306-312, 2010. 
[9] J. Li, H. Zhao, M. Shao, X. Zhou, H. Huang, and Z. Fan, "Design and experiment performances of an inchworm type rotary actuator," Review of Scientific Instruments, vol. 85, no. 8, Article ID 085004, 2014.

[10] Y. Gu and J. Xing, "Dynamics analysis for the clamping mechanisms of a rotary inchworm piezoelectric motor," Journal of Vibroengineering, vol. 18, no. 4, pp. 2229-2239, 2016.

[11] Y. Yamayoshi and S. Hirose, "Ultrasonic motor not using mechanical friction force," International Journal of Applied Electromagnetics in Materials, vol. 3, no. 3, pp. 179-182, 1992.

[12] Y. Yamayoshi, J. Shiina, H. Tamura, and S. Hirose, "Noncontact ultrasonic motor with two flexural standing wave vibration disks," Japanese Journal of Applied Physics, vol. 48, no. 9, pp. 101105, 2009.

[13] C. Chen, F. Li, X. J. Yan et al., "Study on non-contact piezoelectric actuator with spherical rotors," Proceedings of the CSEE, vol. 32, no. 6, pp. 163-169, 2012.

[14] W. Qiu, Y. Hong, Y. Mizuno, W. Wen, and K. Nakamura, "Noncontact piezoelectric rotary motor modulated by giant electrorheological fluid," Sensors and Actuators, A: Physical, vol. 217, pp. 124-128, 2014.

[15] C. Li, J. Xing, and L. Xu, "Coupled vibration of driving sections for an electromechanical integrated harmonic piezodrive system," AIP Advances, vol. 4, no. 3, Article ID 031320, 2014.

[16] C. Li, L.-Z. Xu, and L.-C. Gao, "Nonlinear free vibration of driving system of an electromechanical integrated harmonic piezoelectric motor," Journal of Vibration and Shock, vol. 35, no. 6, pp. 7-12, 2016.

[17] C. Li, L. Xu, and J. Zhang, "Bifurcation and chaotic vibration for an electromechanical integrated harmonic piezodrive system," Journal of Mechanical Science and Technology, vol. 30, no. 7, pp. 2961-2970, 2016. 


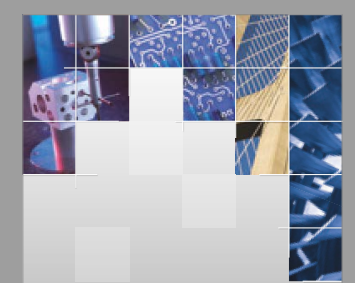

\section{Enfincering}
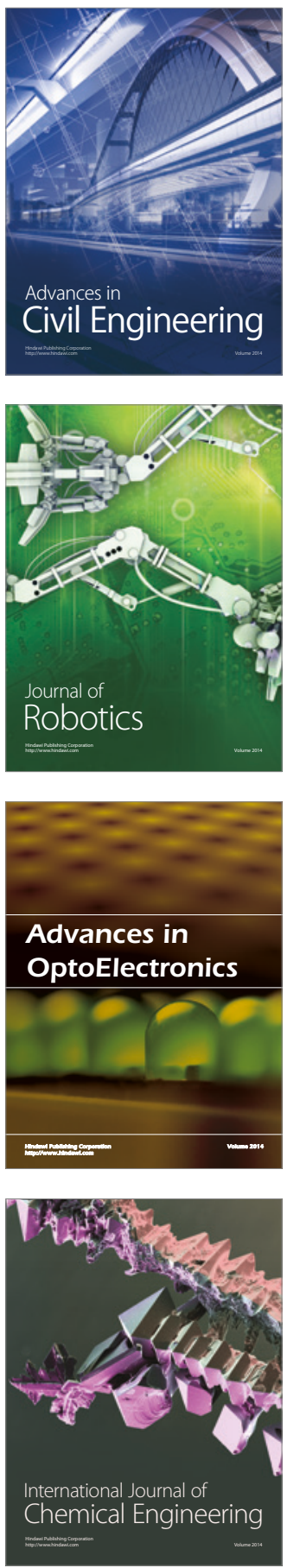

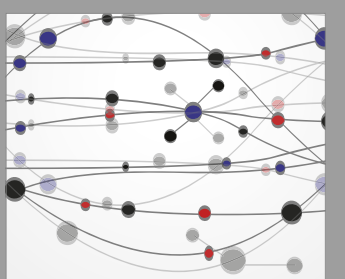

The Scientific World Journal

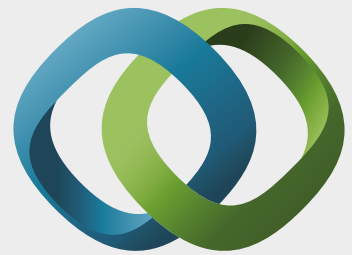

\section{Hindawi}

Submit your manuscripts at

https://www.hindawi.com
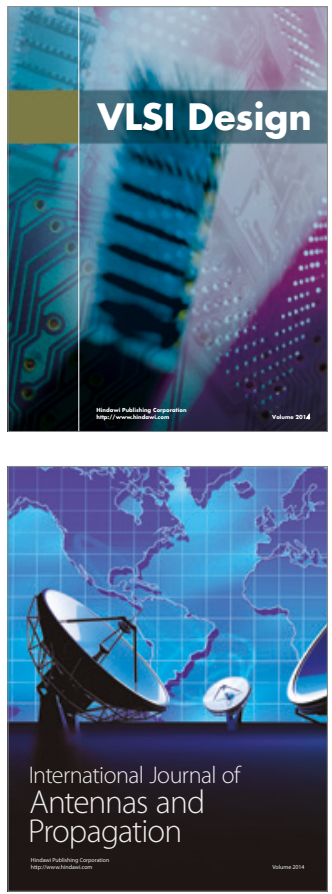

\section{Rotating}

Machinery
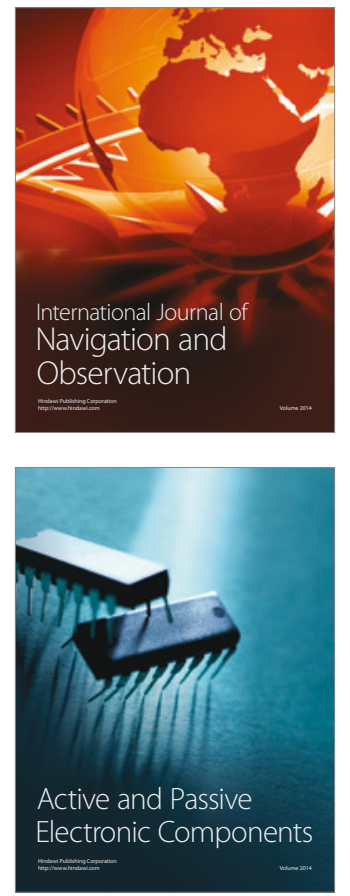
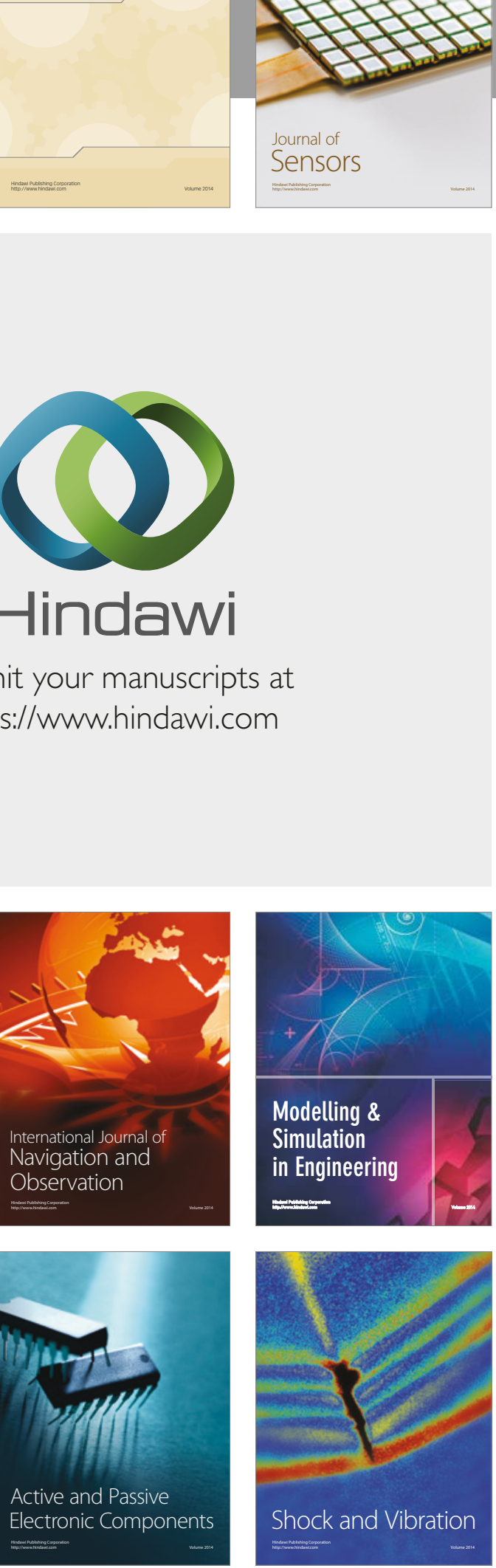
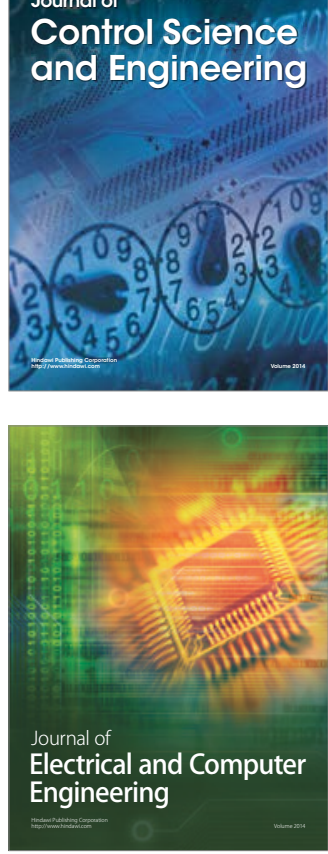

Distributed

Journal of

Control Science

and Engineering
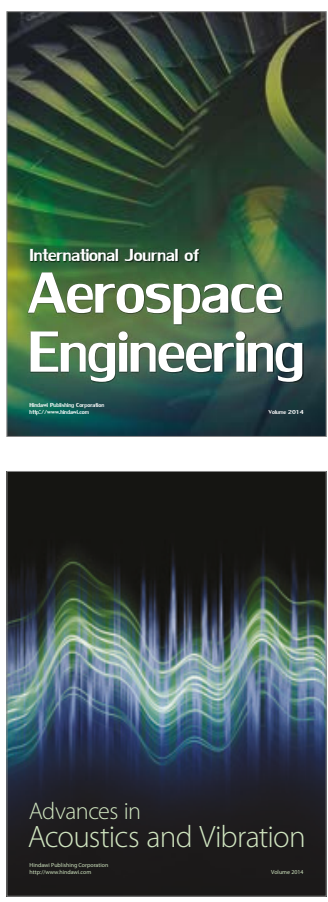

Sensor Networks 